\title{
Hypoxia-inducible factor $2 \alpha$ regulates macrophage function in mouse models of acute and tumor inflammation
}

\author{
Hongxia Z. Imtiyaz, 1,2 Emily P. Williams, ${ }^{2,3}$ Michele M. Hickey, ${ }^{1,2}$ Shetal A. Patel,1,3 Amy C. Durham,4 \\ Li-Jun Yuan,, 5,6 Rachel Hammond,7 Phyllis A. Gimotty, ${ }^{7}$ Brian Keith,1,8 and M. Celeste Simon',2,9 \\ ${ }^{1}$ Abramson Family Cancer Research Institute, ${ }^{2}$ Howard Hughes Medical Institute, ${ }^{3}$ School of Medicine, ${ }^{4}$ School of Veterinary Medicine, and \\ ${ }^{5}$ Department of Medicine and Cardiovascular Institute, University of Pennsylvania, Philadelphia, Pennsylvania, USA. \\ ${ }^{6}$ Tangdu Hospital, Fourth Military Medical University, Xi'an, Shaanxi, China. ${ }^{7}$ Center for Clinical Epidemiology and Biostatistics, \\ ${ }^{8}$ Department of Cancer Biology, and ${ }^{9}$ Department of Cell and Developmental Biology, University of Pennsylvania, Philadelphia, Pennsylvania, USA.
}

\begin{abstract}
Hypoxia-inducible factor $1 \alpha(\mathrm{HIF}-1 \alpha)$ and HIF-2 $\alpha$ display unique and sometimes opposing activities in regulating cellular energy homeostasis, cell fate decisions, and oncogenesis. Macrophages exposed to hypoxia accumulate both HIF-1 $\alpha$ and HIF-2 $\alpha$, and overexpression of HIF-2 $\alpha$ in tumor-associated macrophages (TAMs) is specifically correlated with high-grade human tumors and poor prognosis. However, the precise role of HIF-2 $\alpha$ during macrophage-mediated inflammatory responses remains unclear. To fully characterize cellular hypoxic adaptations, distinct functions of HIF-1 $\alpha$ versus HIF- $2 \alpha$ must be elucidated. We demonstrate here that mice lacking HIF-2 $\alpha$ in myeloid cells ( $H$ if $2 a^{\Delta / \Delta}$ mice) are resistant to lipopolysaccharide-induced endotoxemia and display a marked inability to mount inflammatory responses to cutaneous and peritoneal irritants. Furthermore, HIF-2 $\alpha$ directly regulated proinflammatory cytokine/chemokine expression in macrophages activated in vitro. $\mathrm{Hif} 2 \mathrm{a}^{\Delta / \Delta}$ mice displayed reduced TAM infiltration in independent murine hepatocellular and colitisassociated colon carcinoma models, and this was associated with reduced tumor cell proliferation and progression. Notably, HIF-2 $\alpha$ modulated macrophage migration by regulating the expression of the cytokine receptor M-CSFR and the chemokine receptor CXCR4, without altering intracellular ATP levels. Collectively, our data identify HIF- $2 \alpha$ as an important regulator of innate immunity, suggesting it may be a useful therapeutic target for treating inflammatory disorders and cancer.
\end{abstract}

\section{Introduction}

Macrophages are versatile hematopoietic cells that mediate a wide array of immune functions, e.g., initiating inflammatory responses, executing phagocytosis and bacterial killing, and facilitating adaptive immunity (1-3). The plasticity of macrophages can be represented by two extremes in their activation profile, M1 (or "classical") and M2 (or "alternative") activation (4). The M1 profile is induced by IFN- $\gamma$ and microbial products and primarily exhibits microbicidal activity and a proinflammatory phenotype $(4,5)$, while M2 macrophages (induced by IL-4 or IL-13) are characterized by antiinflammatory properties $(4,5)$. In recent years, increasing attention has focused on tumor-associated macrophages (TAMs), a unique macrophage population that expresses certain M1 products (e.g., CXCL8, TNF- $\alpha$, and IL-6) and M2 compounds (e.g., MMPs, IL-10, CCL17, and CCL22). These factors promote angiogenesis (6-9), facilitate tumor cell invasion, and/or provide an immunosuppressive tumor microenvironment $(7,10)$. The role of TAMs in tumor progression has been controversial. Early reports correlated macrophage infiltration with tumor suppression $(11,12)$. However, other studies suggested that elevated TAM numbers correlate with poor clinical outcome in many types of human cancers $(7,9,10)$. TAM activity is therefore likely to be complex and may be influenced by microenvironmental factors. Interestingly, TAMs migrate toward and accumulate in hypoxic tumor domains (13). When exposed to hypoxia in vitro, macro-

Conflict of interest: The authors have declared that no conflict of interest exists. Citation for this article: J Clin Invest. 2010;120(8):2699-2714. doi:10.1172/JCI39506. phages alter their expression of several mitogenic and proangiogenic cytokines, implying that tumor hypoxia has a profound influence on TAM functions (13-15).

Similarly, sites of inflammation are often associated with ischemia (16). Low oxygen $\left(\mathrm{O}_{2}\right)$ tension arises in inflamed tissues due to vascular damage and edema, as well as intense metabolic activity of bacteria and numerous infiltrating cells. Macrophages accumulate in large numbers within $\mathrm{O}_{2}$-deprived areas in inflammatory lesions, including infections, myocardial infarcts, atherosclerosis, rheumatoid arthritis, wounds, and solid tumors (8, 16-20), suggesting that hypoxic responses may regulate macrophage function during disease progression. Mammalian cells adapt to changes in $\mathrm{O}_{2}$ availability primarily through HIFs whose activity is regulated by their $\alpha$ subunits (HIF- $1 \alpha$ and HIF- $2 \alpha$ ) (21-23). Whereas HIF- $1 \alpha$ appears to be expressed ubiquitously, HIF-2 $\alpha$ is expressed in a more tissue-restricted manner (24-26). Despite their extensive sequence homology, the two $\alpha$ subunits have nonoverlapping and sometimes even opposing roles. For example, HIF- $1 \alpha$ has been documented to exclusively regulate glycolysis (27). In contrast, HIF-2 $\alpha$ (but not HIF-1 $\alpha$ ) directly activates the expression of Oct 4 , a critical transcription factor regulating stem cell maintenance (28), as well as the red blood cell cytokine erythropoietin (29). Furthermore, HIF-1 $\alpha$ inhibits cell proliferation by counteracting c-Myc, while HIF- $2 \alpha$ promotes cell division by enhancing c-Myc activity (30-33). Finally, recent studies have shown that HIF- $1 \alpha$ promotes, whereas HIF- $2 \alpha$ suppresses, the 53 pathway and tumor cell radiosensitivity $(34,35)$. Therefore, the role of HIF- $1 \alpha$ and HIF- $2 \alpha$ in a variety of pathophysiological contexts is complex and incompletely described. 

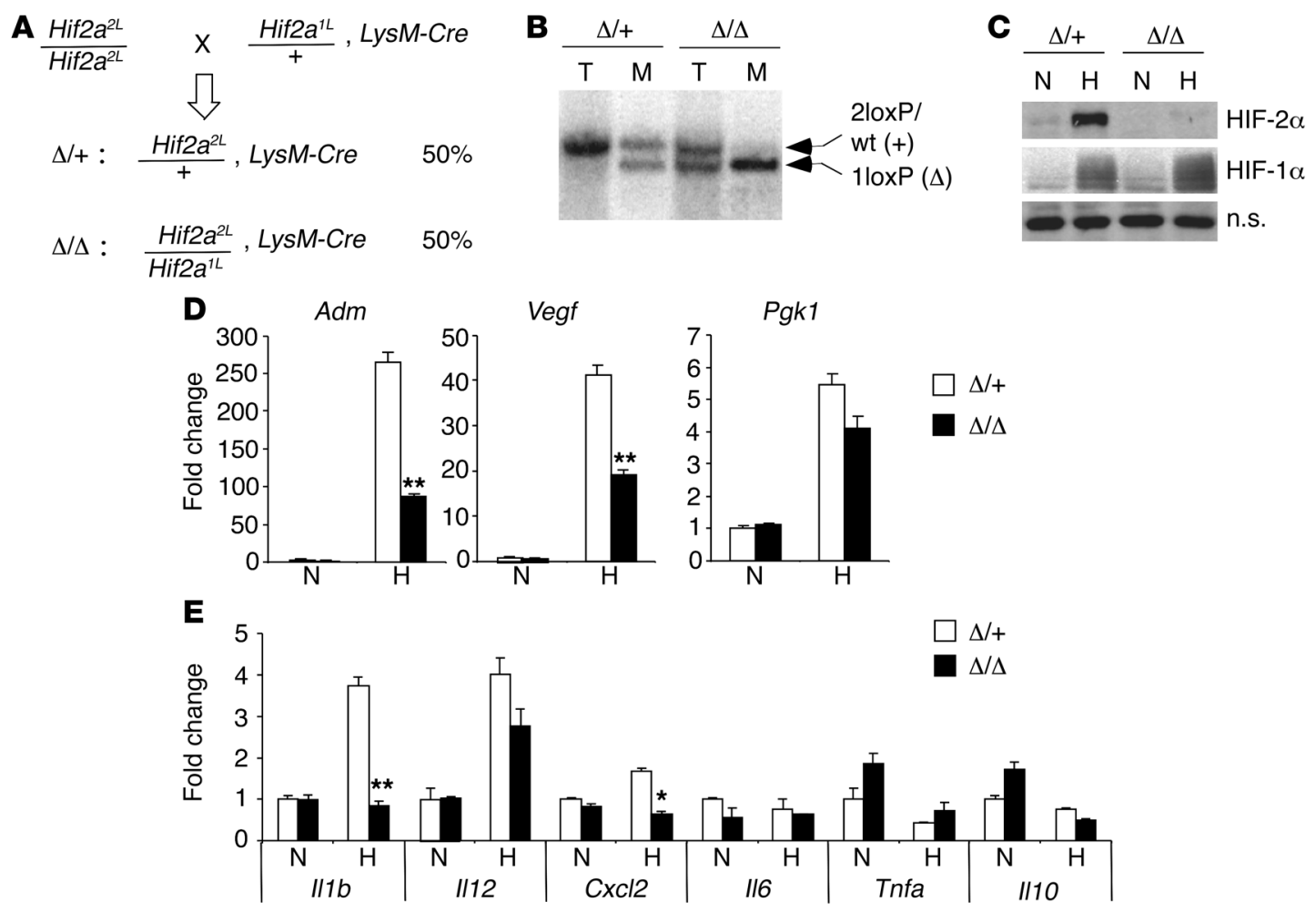

Figure 1

Myeloid-specific ablation of HIF-2 $\alpha$ using LysM-Cre. (A) Breeding scheme used to obtain myeloid-specific HIF-2 $\alpha-$ deficient $\left(H i f 2 a^{\Delta / \Delta}\right.$, i.e., Hif2a $\mathrm{a}^{2 L / 1 L}$, LysM-Cre) and control (Hif2a $\mathrm{a}^{\Delta /+}$, i.e., Hif2a $\mathrm{a}^{2 L /+}$, LysM-Cre) mice. 2L, 2loxP allele; 1L, 1 loxP or deleted allele. Frequency of each genotype is shown. (B) Southern blot showing deletion of the 2loxP allele in macrophages (M). Tail tissue (T) was used as a control. (C) Western blots confirming the absence of HIF-2 $\alpha$ protein under hypoxia in Hif-2 $\alpha^{\Delta / \Delta}$ BMDMs. (D) HIF target expression validating loss of HIF-2 $\alpha$ function in HIF-2 $\alpha$-deficient BMDMs. Data represent fold induction of mRNA expression compared with the control BMDMs. Representative data from 4 independent experiments are shown $\left({ }^{* *} P<0.01\right)$. (E) Cytokine/chemokine expression in normoxic and hypoxic BMDMs was evaluated by QRT-PCR. Representative data from at least 3 independent experiments are shown $\left({ }^{\star} P<0.05,{ }^{* \star} P<0.01\right)$. $\Delta /+$, control genotype, Hif2a ${ }^{\Delta /+} ; \Delta / \Delta$, mutant genotype, Hif2a ${ }^{\Delta / \Delta} ; \mathrm{N}$, normoxia $\left(21 \% \mathrm{O}_{2}\right) ; \mathrm{H}$, hypoxia $\left(0.5 \% \mathrm{O}_{2}\right)$; n.s., nonspecific band.

Both HIF- $1 \alpha$ and HIF- $2 \alpha$ accumulate in hypoxic primary human macrophages and mouse bone marrow-derived macrophages (BMDMs) in vitro $(36,37)$. HIF- $2 \alpha$ protein is also readily detected in vivo in BMDMs and TAMs of various human cancers (38). Myeloid-specific deletion of murine Hifla has revealed an important role for HIF- $1 \alpha$ in mediating macrophage-dependent inflammatory and antibacterial activities (39-41). To evaluate HIF- $2 \alpha$ during inflammation, we bred mice carrying our previously described Hif2a (Epas1, referred to as Hif2a hereafter) conditional allele (29) to a lysozyme M-Cre (LysM-Cre) strain (42) to obtain myeloid lineage-specific deletion of Hif2a. Using LPSinduced endotoxemia and other in vivo models of acute inflammation, we showed that HIF- $2 \alpha$ expression in macrophages is also required for normal inflammatory responses. Furthermore, we identified a critical role for HIF- $2 \alpha$ in regulating proinflammatory cytokine expression in response to M1 stimuli (LPS plus IFN- $\gamma$ ) at low $\mathrm{O}_{2}$, implicating a mechanism whereby hypoxia contributes to the maintenance of a highly inflammatory state. Finally, we tested the function of HIF- $2 \alpha$ in TAMs in the tumor microenvironment using independent autochthonous inflammation-associated murine hepatocellular and colitis-associated carcinoma models. Our data indicate that HIF- $2 \alpha$ is essential for TAM migration into these lesions, which in turn promotes tumor progression.

\section{Results}

Generation of myeloid-specific HIF-2 $\alpha$-null mice. To characterize HIF- $2 \alpha$ function in macrophages, we crossed the floxed Hif $2 a$ allele (29) to LysM-Cre animals (42) (Figure 1A). Progeny carrying the mutant genotype (Hif $2 a^{2 L / 1 L}$, LysM-Cre) were designated Hif $2 a^{\Delta / \Delta}$, whereas progeny carrying the control genotype (Hif $2 a^{2 L /+}$, LysM-Cre) were designated $H i f 2 a^{\Delta /+}$. Littermate controls were used for all experiments conducted. Southern blot analysis of DNA obtained from BMDMs showed approximately $90 \%$ Hif 2 a excision in the genome of mutant macrophages (Figure 1B), consistent with previous reports for this LysM-Cre allele (42). Western blot analysis confirmed HIF-2 $\alpha$ protein loss in mutant BMDMs. As shown in Figure 1C, HIF- $2 \alpha$ protein was stabilized in control (Hif2 $a^{\Delta /+}$ ) but not mutant (Hif $2 a^{\Delta / \Delta}$ ) BMDMs at reduced $\mathrm{O}_{2}$ levels $(0.5 \%)$, whereas HIF- $1 \alpha$ protein was stabilized by hypoxic treatment in both controls and mutants.

To validate HIF-2 $\alpha$ deficiency in unstimulated Hif- $2 \alpha^{\Delta / \Delta}$ BMDMs, we evaluated hypoxic responses of established HIF target genes by real-time quantitative RT-PCR (QRT-PCR). As expected, expression of adrenomedullin $(A d m)$, an HIF-2 $\alpha$ preferential target gene (27, $43,44)$, was elevated approximately 260 -fold in Hif $2 a^{\Delta /+}$ cells upon $\mathrm{O}_{2}$ deprivation. In contrast, $A d m$ mRNA levels decreased by $67 \%$ in hypoxic Hif2 $a^{\Delta / \Delta}$ cells relative to control BMDMs (Figure 1D). Induction of Vegf, a common target gene of both HIF- $1 \alpha$ and HIF- $2 \alpha$, was also reduced, by $53 \%$, in Hif $2 a^{\Delta / \Delta}$ BMDMs compared with con- 

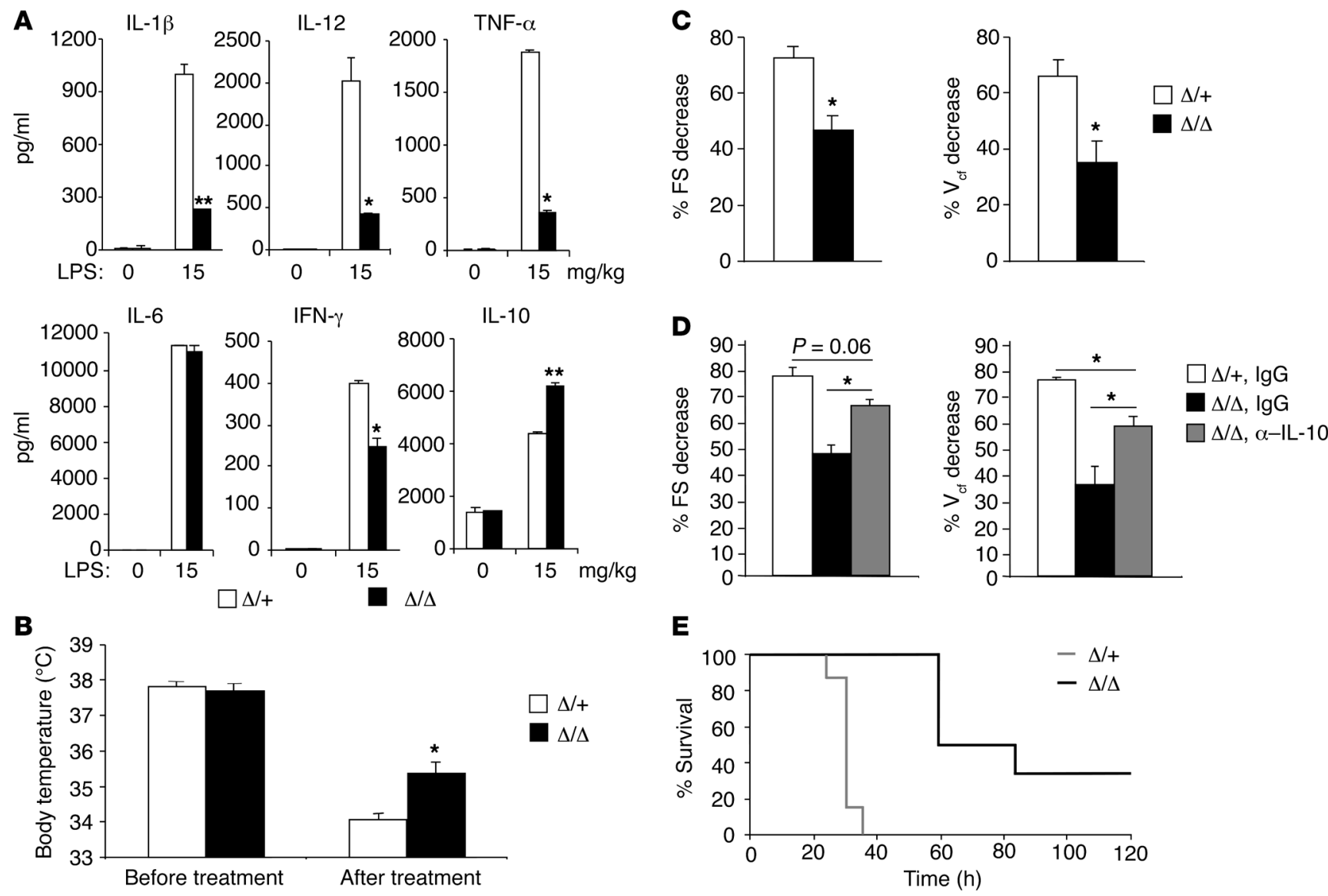

Figure 2

HIF-2 $\alpha$ is critical for cytokine production and cardiac function in LPS-induced endotoxemia. (A) Control $(\Delta /+)$ and mutant $(\Delta / \Delta)$ mice were challenged with LPS (15 mg/kg body weight) via i.p. injection; serum was obtained 4 hours following the challenge; and cytokine levels were determined using ELISA. Representative data from 5 mice per group are shown $\left({ }^{*} P<0.05,{ }^{* \star} P<0.01\right)$. (B) Hif2a $a^{\Delta / \Delta}$ animals maintained body temperature better than controls 4 hours following LPS treatment (Hif2a ${ }^{\Delta+}, n=3 ;$ Hif2a $\left.{ }^{\Delta / \Delta}, n=6\right)\left({ }^{\star} P<0.05\right)$. (C) Echocardiography showed better LV function in mutant mice 4 hours following LPS treatment (Hif2 $\mathrm{a}^{\Delta /+}, n=3$; Hif2 $\left.\mathrm{a}^{\Delta / \Delta}, n=6\right)\left({ }^{\star} P<0.05\right)$. (D) Mutant mice were pretreated with either anti-IL-10 antibody or isotype control IgG, and their LV function was examined 4 hours following LPS induction of endotoxemia $(n=3)\left({ }^{*} P<0.05\right)$. (E) A Kaplan-Meier curve representing survival of animals challenged with LPS (Hif2a $\mathrm{a}^{\Delta+}, n=7 ;$ Hif2 $^{\mathrm{L} / \Delta}, n=6$; log-rank statistic $\left.=12.50, P=0.0004\right)$.

trols. Conversely, Pgk1, an HIF-1 $\alpha$-specific target gene (27), was induced to similar levels in both genotypes when cultured at $0.5 \%$ $\mathrm{O}_{2}$ (Figure 1D). These results confirmed the loss of HIF- $2 \alpha$ transcriptional activity in Hif2 $a^{\Delta / \Delta}$ BMDMs. As hypoxia stimulates the expression of the proinflammatory cytokine macrophage migration inhibitory factor (MIF) (45) and the chemokine CXCL2 (also known as macrophage inflammatory protein-2 [MIP-2]) in macrophages $(46,47)$, we investigated the expression of other M1-associated proinflammatory cytokine/chemokine mRNAs in response to hypoxia (Figure 1E). Cxcl2 expression was induced ( 2-fold) by hypoxia $\left(0.5 \% \mathrm{O}_{2}\right)$, consistent with previous reports. $I l 1 b$ expression was also enhanced (2- to 4 -fold) by hypoxia $\left(0.5 \% \mathrm{O}_{2}\right)$. Of note, both $I l 1 b$ and $C x c l 2$ upregulation were dependent on HIF- $2 \alpha$. However, Il12, Il6, Tnfa, and Il10 mRNA levels were similar in control and mutant macrophages.

As LysM-Cre initiates gene deletion within early hematopoietic progenitor cells, we investigated whether HIF-2 $\alpha$ deficiency influences macrophage differentiation. We analyzed bone marrow myeloid progenitor populations, including common myeloid progenitors (CMPs), bipotential granulocyte/macrophage progeni- tors (GMPs), and megakaryocyte/erythrocyte progenitors (MEPs), using established surface markers (48). No significant difference between mutant and control mice was observed for CMPs $\left(1.21 \% \pm 0.51 \%\right.$ in Hif $2 a^{\Delta / \Delta}$ vs. $1.08 \% \pm 0.22 \%$ in Hif $\left.2 a^{\Delta /+}\right)$, GMPs $\left(0.97 \% \pm 0.33 \%\right.$ in $H i f 2 a^{\Delta / \Delta}$ vs. $0.70 \% \pm 0.24 \%$ in Hif2 $\left.a^{\Delta /+}\right)$, or MEPs $\left(0.67 \% \pm 0.11 \%\right.$ in Hif $2 a^{\Delta / \Delta}$ vs. $0.57 \% \pm 0.15 \%$ in Hif $\left.2 a^{\Delta /+}\right)(n=4)$ (Supplemental Figure 1A; supplemental material available online with this article; doi:10.1172/JCI39506DS1), suggesting that myeloid progenitors are not affected by the loss of HIF- $2 \alpha$. Subsequent macrophage maturation was not significantly perturbed, as evidenced by normal numbers of $\mathrm{CD} 11 \mathrm{~b}^{+} \mathrm{F} 4 / 80^{+}$monocytes and $\mathrm{CD} 11 \mathrm{~b}^{+} \mathrm{F} 4 / 80^{+} \mathrm{MHC}$ class $\mathrm{II}^{+}$macrophages (data not shown). In addition, we analyzed survival and proliferation of isolated BMDMs and found that HIF-2 $\alpha$ deficiency did not lead to defects in these processes (Supplemental Figure 1, B and C).

Since LysM-Cre is also active in neutrophils, we evaluated the effect of Hif2a deletion on this lineage. However, whereas bone marrow-derived neutrophils clearly express HIF-1 $\alpha$, we were unable to detect HIF-2 $\alpha$ mRNA (Supplemental Figure $2 \mathrm{~A}$ ) or protein (Supplemental Figure 2B), consistent with previous reports 
A

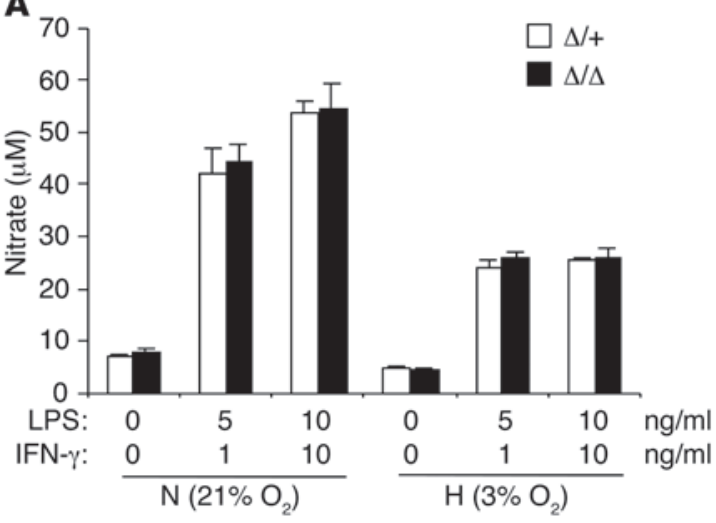

B

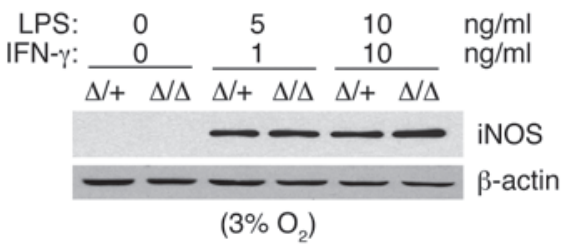

C

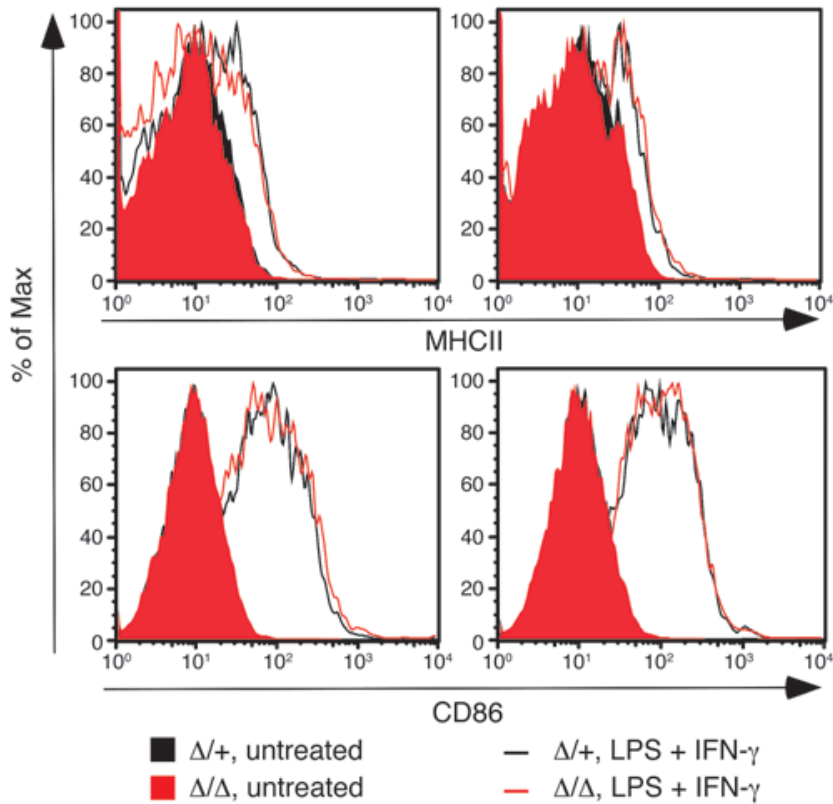

Figure 3

NO production and activation marker expression are not affected by loss of HIF-2 $\alpha$. (A) BMDMs were stimulated with various concentrations of LPS plus IFN- $\gamma$ for 24 hours; NO production was evaluated by measuring nitrate concentration in the culture supernatant using the Griess assay; $n=7$. (B) iNOS expression following stimulation with various concentrations of LPS plus IFN- $\gamma$ under $3 \% \mathrm{O}_{2}$ was assayed by Western blotting. No difference was found between the control and HIF-2 $\alpha$-deficient macrophages. (C) Upregulation of cell surface activation markers (MHC class II and CD86) in response to LPS plus IFN- $\gamma$ was not affected by lack of HIF-2 $\alpha$ in macrophages under either normoxia or hypoxia.

$(49,50)$. Likewise, HIF- $2 \alpha$ was not expressed in MPRO cells, a mouse neutrophil cell line, regardless of oxygen levels (Supplemental Figure 2, C and D). To investigate whether inflammatory agents induce HIF-2 $\alpha$ expression, we stimulated MPRO cells with the phorbol ester 12-O-tetradecanoylphorbol-13-acetate (TPA) under normoxia and hypoxia. As shown in Supplemental Figure 2, C and D, no HIF- $2 \alpha$ mRNA or protein was detected upon TPA treatment. In contrast, cell surface expression of CD11b increased, confirming the activation status of these cells (Supplemental Figure $2 \mathrm{E}$ ). It was consequently not surprising that neutrophil differentiation was unaffected by HIF- $2 \alpha$ deficiency, and comparable neutrophil numbers were observed in Hif $2 a^{\Delta / \Delta}$ and Hif $2 a^{\Delta /+}$ bone marrow, spleen, and peripheral blood (Supplemental Figure 2F).

It has been reported that LysM-Cre has partial activity (16\%-31\%) in DCs (42). To measure Hif $2 a$ deletion in DCs, we performed PCR on genomic DNA obtained from bone marrow-derived DCs. Consistent with previous reports, the floxed allele (2loxP) was only partially recombined by LysM-Cre (Supplemental Figure 3A). Although DCs from Hif2 $a^{\Delta / \Delta}$ mice exhibited slightly less Hif2a mRNA than DCs from control animals, this subtle difference was not reflected at the level of protein (Supplemental Figure 3, B and C). Also, equivalent HIF-2 $\alpha$ protein accumulation was detected between Hif $2 a^{\Delta / \Delta}$ and Hif $2 a^{\Delta / \Delta}$ DCs upon LPS-induced maturation, further confirming largely insufficient LysM-Cre activity in this lineage. Therefore, the primary myeloid cells that experience Hif2a deletion and show functional relevance in $H$ if $2 a^{\Delta / \Delta}$ mice are cells of the monocyte/macrophage lineage.

HIF-2 $\alpha$ expression in macrophages is critical for inflammatory responses during LPS-induced endotoxemia. To evaluate the role of myeloid HIF- $2 \alpha$ in inflammatory responses, we injected Hif $2 a^{\Delta /+}$ and Hif $2 a^{\Delta / \Delta}$ mice i.p. with $15 \mathrm{mg} / \mathrm{kg}$ LPS to produce endotoxemia. This model causes systemic inflammation by producing high levels of circulating proinflammatory cytokines, similar to animal models of sepsis. IL-1 $\beta$, IL-12, TNF- $\alpha$, and IFN- $\gamma$ have all been implicated in the toxic effects of endotoxemia, and neutralization of these cytokines by specific antibodies protects mice from LPS-induced lethality (51-58). We therefore tested whether HIF-2 $\alpha$ deficiency in macrophages affects LPS-induced cytokine responses. As shown in Figure 2A, serum levels of IL- $1 \beta$, IL-12, TNF- $\alpha$, IL-6, and IFN- $\gamma$ were dramatically increased in endotoxemic Hif $2 a^{\Delta /+}$ mice 4 hours after injection. In contrast, the induction of IL-1 $\beta$, IL-12, and TNF- $\alpha$ was significantly reduced (by approximately $80 \%$ ) in Hif $2 a^{\Delta / \Delta}$ mice compared with controls. IFN- $\gamma$ levels were also reduced in Hif $2 a^{\Delta / \Delta}$ mice (by approximately $40 \%$ ) relative to $H i f 2 a^{\Delta /+}$ animals. In contrast, levels of IL-6 were comparable between control and mutant serum samples (Figure 2A). Interestingly, we found that the antiinflammatory cytokine IL-10 was moderately elevated by LPS (on average, 1.5 -fold) in mutant animals compared with controls (Figure 2A). As LPS is also known to induce hypothermia in mice (59), we measured mouse core temperature using a rectal temperature probe. Control mice showed decreased core temperature upon LPS treatment (Figure 2B). However these decreases were modestly but reproducibly attenuated in $\mathrm{Hif} 2 \mathrm{a}^{\mathrm{\Delta} / \Delta}$ animals $\left(35.4 \pm 0.34^{\circ} \mathrm{C}\right.$ in Hif $2 a^{\Delta / \Delta}$ mice, $n=3$ vs. $34.1 \pm 0.17^{\circ} \mathrm{C}$ in Hif $2 a^{\Delta /+}$ mice, $n=6 ; P=0.043$ ) (Figure $2 \mathrm{~B}$ ). Based on circulating cytokine and hypothermia measurements, we concluded that Hif $2 a^{\Delta / \Delta}$ animals are more resistant to LPS-induced endotoxemia.

Systemic inflammation caused by LPS could trigger multiorgan failure, including cardiovascular collapse (60). Proinflammatory cytokines, particularly TNF- $\alpha$ and IL- $1 \beta$, are important mediators of 
A
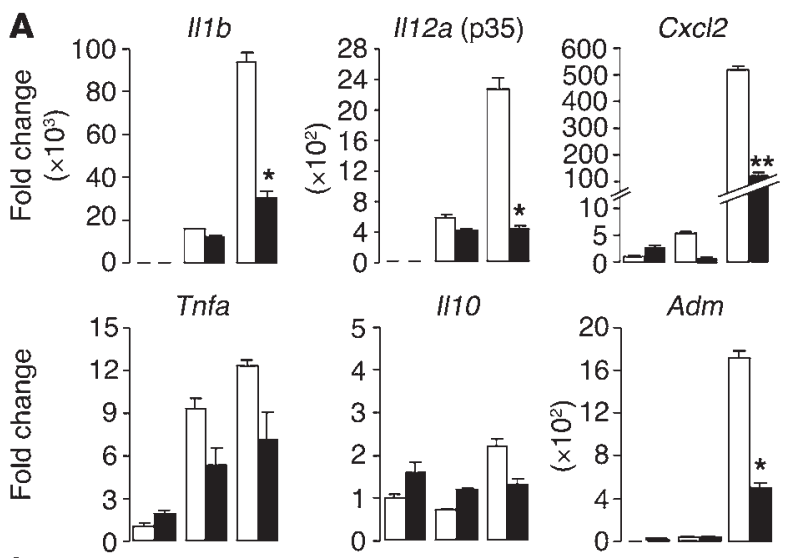

LPS + IFN-y: -++ Hypoxia: - -+
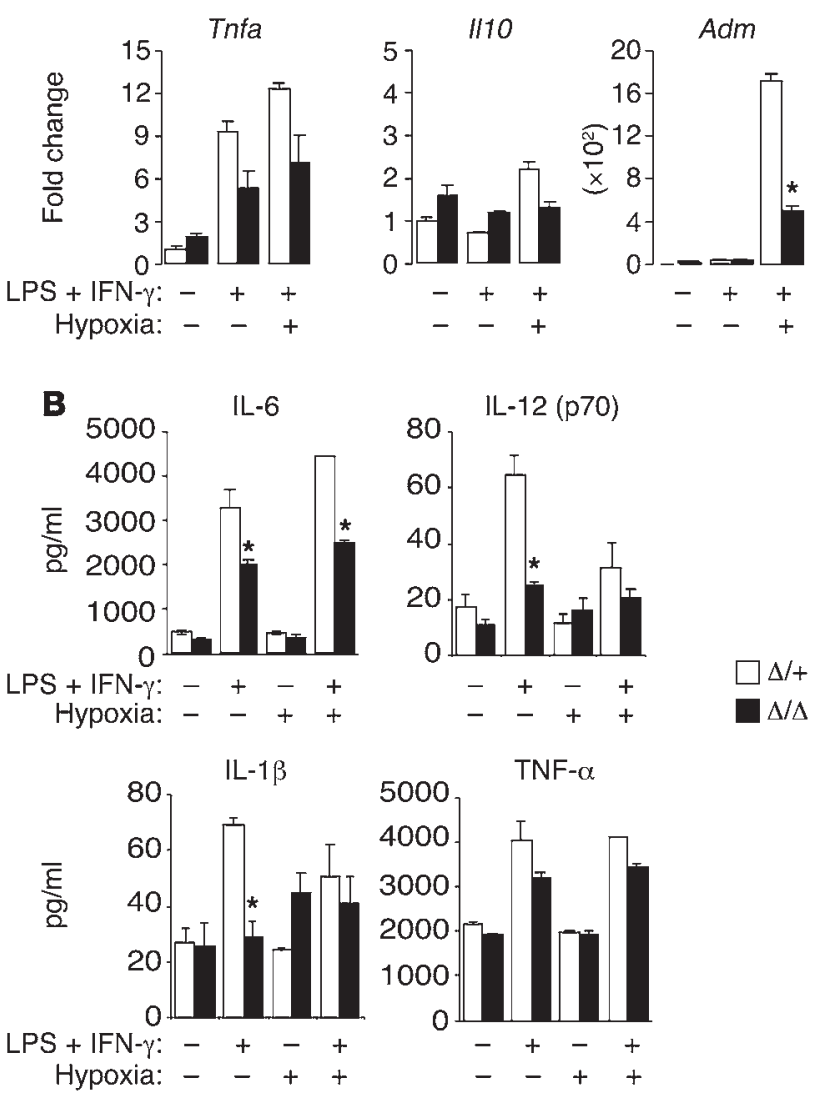

the toxic effects of LPS on cardiac function $(58,61)$, and macrophages are thought to be responsible for LPS-induced myocardial impairment (62). Given that myeloid HIF-2 $\alpha$ deficiency caused defective IL-1 $\beta$ and TNF- $\alpha$ expression upon LPS treatment, we tested whether this correlates with improved myocardial function. Two parameters indicating LV contractility, LV fractional shortening (FS) and velocity of $L V$ circumferential fiber shortening $\left(V_{c f}\right)(63,64)$, were assessed by echocardiography. As shown in Figure 2C, LV FS was decreased in control mice by more than $70 \%$ upon LPS treatment. However, Hif $2 a^{\Delta / \Delta}$ mice had a relatively moderate change $(46.9 \% \pm 4.93 \%$ in Hif $2 a^{\Delta / \Delta}, n=3$ vs. $72.3 \% \pm 4.13 \%$ in Hif $2 a^{\Delta /+}, n=6 ; P=0.013$ ), suggesting better $L V$ function. Similarly, the $L V V_{c f}$ reduction was less dramatic in $H$ if $2 a^{\Delta / \Delta}$ mice compared with controls $(35.1 \% \pm 7.65 \%$ in Hif $2 a^{\Delta / \Delta}, n=3$ vs. $66.0 \% \pm 5.65 \%$ in Hif $\left.2 a^{\Delta /+}, n=6 ; P=0.034\right)$, confirming the cardiac phenotype. Therefore, myeloid HIF- $2 \alpha$ deficiency protects mice, at least in part, from LPS-induced cardiac impairment. Although local leukocyte infiltration can affect cardiac performance, we observed no difference in leukocyte numbers between control and mutant hearts (data not shown). The protective effect observed in Hif $2 a^{\Delta / \Delta}$ mice is more likely to be due to decreased serum levels of proinflammatory cytokines, which have been strongly implicated in the pathogenesis of murine endotoxemia $(57,58)$.

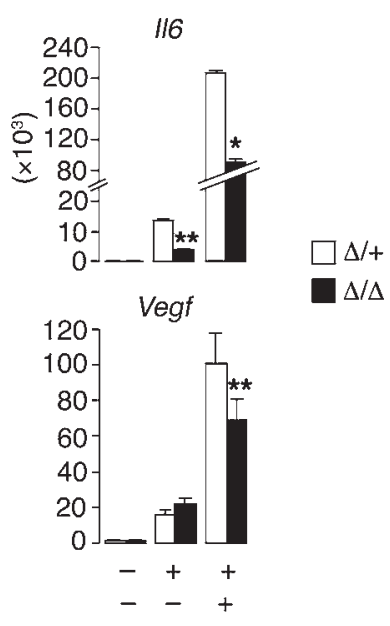

\section{Figure 4}

Proinflammatory cytokine expression is aberrant in Hif2a $\mathrm{a}^{\Delta / \Delta} \mathrm{BMDMs}$ responding to low $\mathrm{O}_{2}$ and $\mathrm{M} 1$ stimuli. (A) BMDMs were treated with $\mathrm{M} 1$ ( $5 \mathrm{ng} / \mathrm{ml}$ LPS plus $1 \mathrm{ng} / \mathrm{ml}$ IFN- $\gamma$ ) stimuli under normoxia or hypoxia for 24 hours, and their expression of cytokines/chemokines (as shown) was evaluated by QRT-PCR. Representative data from at least 3 independent experiments are shown $\left({ }^{\star} P<0.05,{ }^{* *} P<0.01\right)$. (B) BMDMs were activated for 36 hours using LPS $(5 \mathrm{ng} / \mathrm{ml})$ plus IFN- $\gamma(1 \mathrm{ng} / \mathrm{ml})$ under normoxia or hypoxia, and culture supernatant was obtained for measurement of secreted cytokine levels via ELISA. Representative data from at least 3 independent experiments are shown $\left({ }^{\star} P<0.05\right)$. Hypoxia: $0.5 \% \mathrm{O}_{2}$.
During LPS-induced endotoxemia, the antiinflammatory cytokine IL-10 is released into peripheral blood and protects mice from endotoxic shock (65-67), in part by antagonizing proinflammatory cytokines such as TNF- $\alpha$ and IFN- $\gamma(68)$. To define a functional role for elevated IL-10 levels in endotoxemic mutant mice, we administrated neutralizing anti-IL-10 antibody or isotype control IgG 2 hours before LPS challenge and examined cardiac performance in these mice. As shown in Figure 2D, Hif $2 a^{\Delta / \Delta}$ mice receiving anti-IL-10 displayed significantly decreased LV FS and $V_{\mathrm{cf}}$ compared with IgG-treated animals. However, the reversal of this phenotype by IL-10 neutralization was not complete when compared with IgG-treated control mice. These data suggest that elevated IL-10 confers some, but not all, protection of cardiac function in Hif $2 a^{\Delta / \Delta}$ endotoxemic mice (Figure 2C). Thus, coordinated suppression of proinflammatory cytokines and promotion of antiinflammatory factors are both important for the cardiac phenotype observed in Hif $2 a^{\Delta / \Delta}$ mice. Taken together, our results revealed a complex role for macrophage HIF- $2 \alpha$ in modulating both proinflammatory and antiinflammatory axes during LPS-induced endotoxemia, which consequently affects the severity of myocardial depression.

To determine whether the shift in cytokine balance and improvement in cardiac performance in mutant animals translated to a 
A

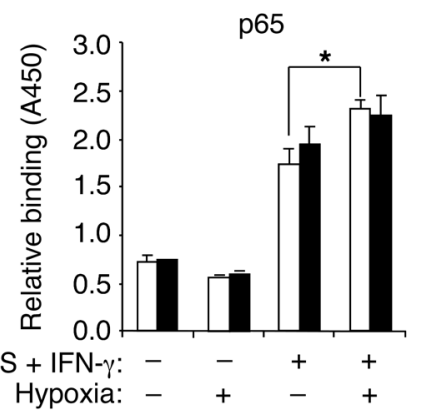

C

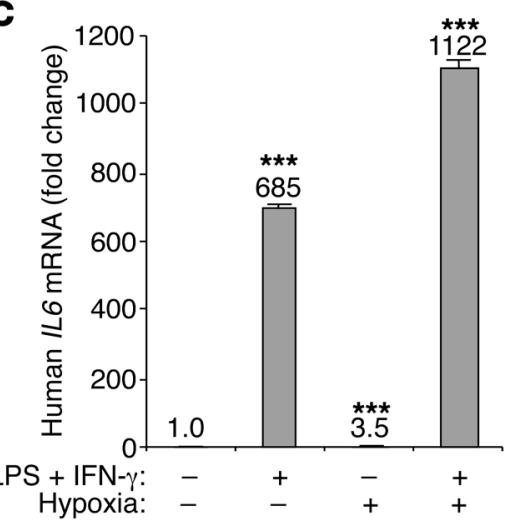

RelB

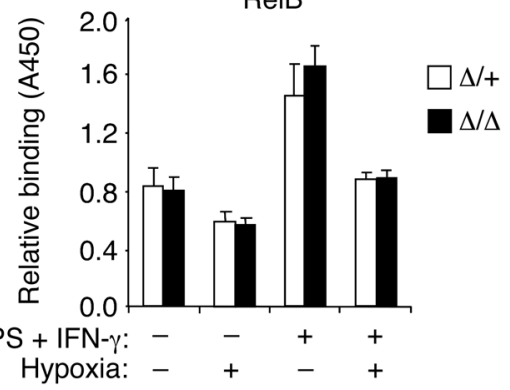

B

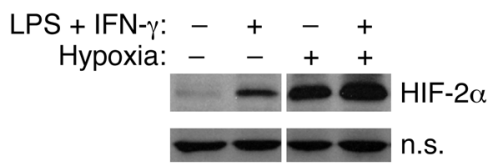

\section{D}
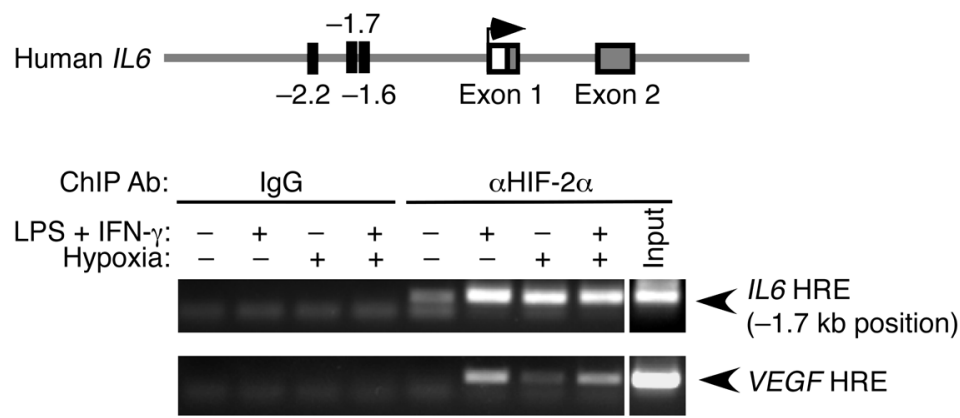

\section{Figure 5}

HIF-2 $\alpha$ directly regulates cytokine gene expression. (A) HIF-2 $\alpha$-regulated cytokine expression does not involve NF- $\kappa$ B. BMDMs were treated with

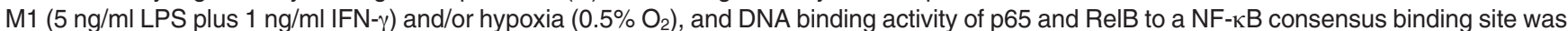
assessed using TransAM NFKB Family Transcription Factor Assay Kit (Active Motif). Though hypoxia appears to enhance M1-induced p65 binding activity, no significant difference was observed between the control and Hif2a-deficient groups $(n=3)\left({ }^{\star} P<0.05\right)$. (B) U937 cells were differenti-

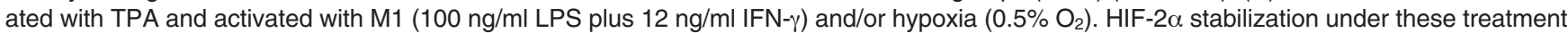
conditions was examined by Western blotting. Lanes were run on the same gel but were noncontiguous (white lines). (C) IL6 expression in U937 cells under various treatment conditions was determined by QRT-PCR. ( $\left.{ }^{* \star *} P<0.001\right)$ (D) ChIP was performed on U937 cells to assess binding of HIF-2 $\alpha$ protein to potential HRE motifs located at $-2.2 \mathrm{~kb},-1.7 \mathrm{~kb}$, and $-1.6 \mathrm{~kb}$ upstream of transcriptional starting site in promoter regions of the IL6 gene. The VEGF gene was used as a positive control. Lanes were run on the same gel but were noncontiguous (white lines).

survival benefit, we recorded mortality of the animals following LPS treatment. As shown in Figure 2E, Hif $2 a^{\Delta / \Delta}$ mice exhibited a significantly enhanced survival $(P=0.0004)$ over the course of the experiment. This result further confirmed the finding that macrophage HIF- $2 \alpha$ exacerbates pathological outcomes of the LPSinduced endotoxemia, likely through the regulation of inflammatory cytokine production.

M1-induced NO production and activation molecule expression are unaltered in Hif $2 a^{\Delta / \Delta}$ macrophages. To define mechanism(s) underlying the influences of HIF- $2 \alpha$ on endotoxemia-associated inflammatory responses and myocardial impairment, we activated BMDMs using LPS and IFN- $\gamma$ and analyzed M1-associated responses in vitro. M1 stimulation of LPS- and IFN- $\gamma$-activated macrophages led to the production of reactive nitrogen and oxygen species, resulting in major microbicidal activity and tissue injury. Interestingly, no significant difference in NO levels was observed between control and Hif $2 a^{\Delta / \Delta}$ BMDMs in response to M1 stimulation under either normoxia or hypoxia (Figure 3A). Similarly, iNOS expression following M1 treatment was similar in activated hypoxic Hif $2 a^{\Delta / \Delta}$ and Hif2 $a^{\Delta /+}$ macrophages (Figure 3B).

Activated macrophages also serve as professional antigen-presenting cells by upregulating MHC class II and costimulatory surface molecules. As expected, LPS and IFN- $\gamma$ treatment induced
MHC class II and CD86 expression, although levels were comparable under normoxia and hypoxia, and HIF- $2 \alpha$ deficiency had no effect under any condition (Figure 3C). Therefore, HIF- $2 \alpha$ is dispensable for $\mathrm{NO}$ production and $\mathrm{MHC}$ class II or costimulatory molecule expression in macrophages.

$H I F-2 \alpha$ regulates $M 1$-stimulated proinflammatory cytokine expression. As HIF- $2 \alpha$ regulated the expression of proinflammatory cytokines in resting $\mathrm{BMDMs}$ responding to low $\mathrm{O}_{2}$ (Figure 1), we investigated the effects of M1 stimulation on IL-1 $\beta$, IL-12, IL-6, TNF- $\alpha$, and CXCL2 expression in LPS- and IFN- $\gamma$-activated macrophages in vitro (Figure 4). When combined with M1 stimulation, hypoxic treatment dramatically enhanced the expression of transcripts encoding IL- $1 \beta(93,700$ fold), IL-12 (2,270-fold), CXCL2 (537-fold), and IL-6 (207,000-fold) in control activated macrophages. This response was clearly HIF- $2 \alpha$ dependent, as hypoxic induction was significantly reduced in Hif $2 a^{\Delta / \Delta}$ macrophages (by $68 \%$ for $I l 1 b, 81 \%$ for $I l 12,77 \%$ for $C x c l 2$, and $56 \%$ for $I l 6$ ) (Figure 4A). The reduction in Il6 expression in LPS- and IFN- $\gamma$-stimulated Hif $2 a^{\Delta / \Delta}$ macrophages was unexpected, as resting BMDMs (Figure 1) and endotoxemic mice (Figure 2A) showed no HIF- $2 \alpha$-dependent differences in IL- 6 expression. It appears that although IL- 6 expression is decreased in activated mutant macrophages in vitro, other cell types (e.g., vascular endothelial cells) contribute to IL-6 production in endotoxemic mice, as previously report- 


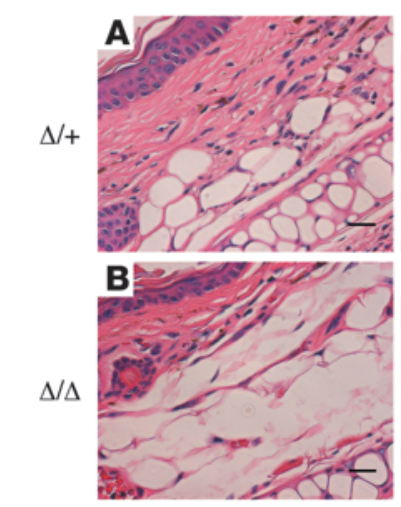

Acetone
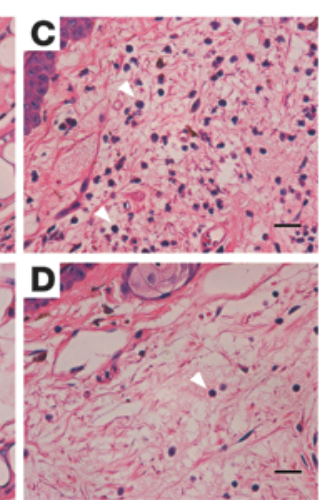

TPA
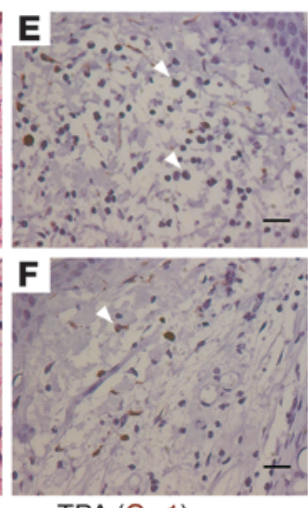

TPA (Gr-1)

H

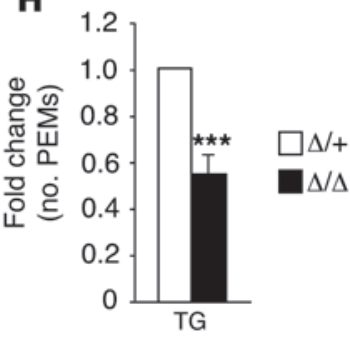

\section{Figure 6}

HIF-2 $\alpha$ is required for TPA- and TG-induced inflammation. (A-G) TPA-induced acute ear inflammation is impaired in myeloid HIF- $2 \alpha-$ deficient mice. (A-D) Ear skin was painted with either acetone (control) or TPA; ear tissue was harvested 24 hours later and stained with H\&E. Scale bars: $20 \mu \mathrm{m}$. (E and F) Ear tissue was stained with Gr-1 antibody to confirm that the majority of infiltrating cells are PMNs. Scale bars: $20 \mu \mathrm{m}$. (G) Infiltrating cells (based on H\&E staining) and $\mathrm{Gr}-1^{+}$cells were counted under highpower $(\times 40)$ fields $\left(n=3,{ }^{*} P<0.05\right)$. (H) Myeloid HIF-2 $\alpha$-deficient mice displayed reduced total number of TG-elicited peritoneal exudate macrophages (PEMs) $\left(n=5,{ }^{* * \star} P<0.001\right)$. Arrowheads in $\mathbf{C}, \mathbf{D}, \mathbf{E}$, and $\mathbf{F}$ indicate neutrophils.

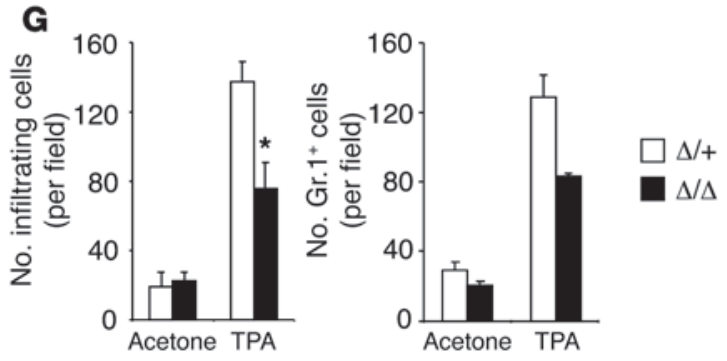

ed (69). Interestingly, several cytokines were expressed at reduced levels in Hif2 $a^{\Delta / \Delta}$ BMDMs treated with LPS and IFN- $\gamma$ even at $21 \% \mathrm{O}_{2}$ (Figure 4A), suggesting that baseline normoxic HIF-2 $\alpha$ levels may be functionally relevant. M1 induction of another proinflammatory cytokine, Tnfa, was only marginally enhanced by hypoxia and was less dependent on HIF-2 $\alpha$, suggesting that HIF-2 $\alpha$ proinflammatory responses are selective. In contrast, the antiinflammatory cytokine Il10 was not induced during M1 activation (Figure 4A), although M1 activation combined with hypoxia produced a slight but statistically insignificant increase in $I l 10$ levels.

To extend these results, we performed ELISAs to measure cytokine release from activated macrophages in vitro. Consistent with the mRNA data above, M1-induced IL-6, IL-12, and IL-1 $\beta$ secretion was reduced in $H$ if $2 a^{\Delta / \Delta}$ macrophages to approximately $40 \%-60 \%$ of that in controls (Figure 4B). Collectively, the data indicate that hypoxia amplified macrophage production of proinflammatory cytokines in a HIF- $2 \alpha$-dependent manner. In summary, our results are consistent with a model in which IL-1 $\beta$ and IL-12 in serum of endotoxemic mice are produced primarily by activated macrophages, whereas other cytokines such as IL-6 may also be contributed by other cell types.

HIF-2 $\alpha$ directly regulates cytokine gene expression. LPS is a TLR4 ligand and activates MyD88- and Trif-dependent pathways in macrophages, resulting in activation of transcription factors NF- $\kappa B$, activator protein 1 (AP-1), and interferon regulatory factor 3 (IRF3) (70). As NF- $\mathrm{KB}$ is a known regulator of IL-1 $\beta$, IL-6, and CXCL2 (71), we hypothesized that hypoxia may amplify M1-induced cytokine

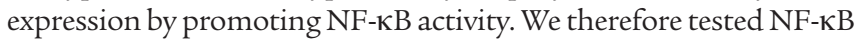
DNA-binding activity in $H$ if $2 a^{\Delta /+}$ and $H$ if $2 a^{\Delta / \Delta}$ BMDMs activated by M1 stimuli and/or hypoxia for 18 hours. As shown in Figure 5A, hypoxia treatment alone did not activate $\mathrm{p} 65$, a member of the clas-

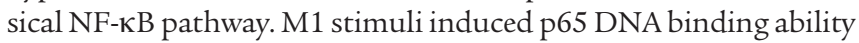
in control macrophages, which increased moderately under hypoxia (1.3-fold, $n=3, P=0.0384)$; however, both responses were HIF- $\alpha$ independent (Figure 5A). Interestingly, M1-stimulated RelB and p52 (components of the alternative NF- $\mathrm{KB}$ pathway) activity were inhibited by hypoxia, but once again this effect was not attributable to HIF-2 $\alpha$ (Figure 5A and data not shown). Therefore, there is no apparent crosstalk between HIF- $2 \alpha$ and NF- $\kappa \mathrm{B}$ in regulating macrophage proinflammatory cytokine expression.

As shown in Figure 4A, M1 stimuli activated HIF-2 $\alpha$ targets such as $A d m$ and Vegf in macrophages, and combined M1 and hypoxic treatment synergistically increased expression of both genes. A similar activation pattern was observed for $I l 1 b, I l 12 a, C x c l 2$, and Il6 (see above), implying that proinflammatory cytokine genes may be directly regulated by HIF- $2 \alpha$. Using ChIPs, we assessed HIF- $2 \alpha$ binding to promoter region of the IL6 locus. U937, a human pro-myelomonocytic leukemia cell line, was employed for these experiments, as large numbers of cells are required to facilitate immunoprecipitation assays. Upon differentiation using the phorbol ester TPA, U937 cells were treated with M1 stimuli and/or hypoxia. HIF-2 $\alpha$ protein accumulated in these cells upon either M1 or hypoxia treatment; moreover, combined M1 and hypoxia treatment further stabilized HIF-2 $\alpha$ (Figure 5B). Similarly, expression of IL6 mRNA could be induced by M1 or hypoxia, although to a much lesser extent for the latter (Figure 5C). Combined treatment resulted in enhanced Il6 expression. We then screened the promoter region of IL6 (up to $-4.0 \mathrm{~kb} \mathrm{5'-FS)}$ and identified 3 putative hypoxia responsive elements (HREs) (72) located at -1.6-, -1.7-, and -2.2-kb positions. As shown by ChIP assay, the sequence located at $-1.7 \mathrm{~kb}$ specifically bound HIF- $2 \alpha$ protein when induced by M1 stimuli, hypoxia, or both (Figure 5D). A similar HIF-2 $\alpha$ binding pattern was observed for the established HRE present in the VEGF promoter. Moreover, we detected a relatively weak interaction between HIF- $2 \alpha$ and a second sequence located at the $-2.2-\mathrm{kb}$ position (data not shown). We concluded that HIF- $2 \alpha$ physically associates with the IL6 gene and transcriptionally regulates its expression in macrophages. 

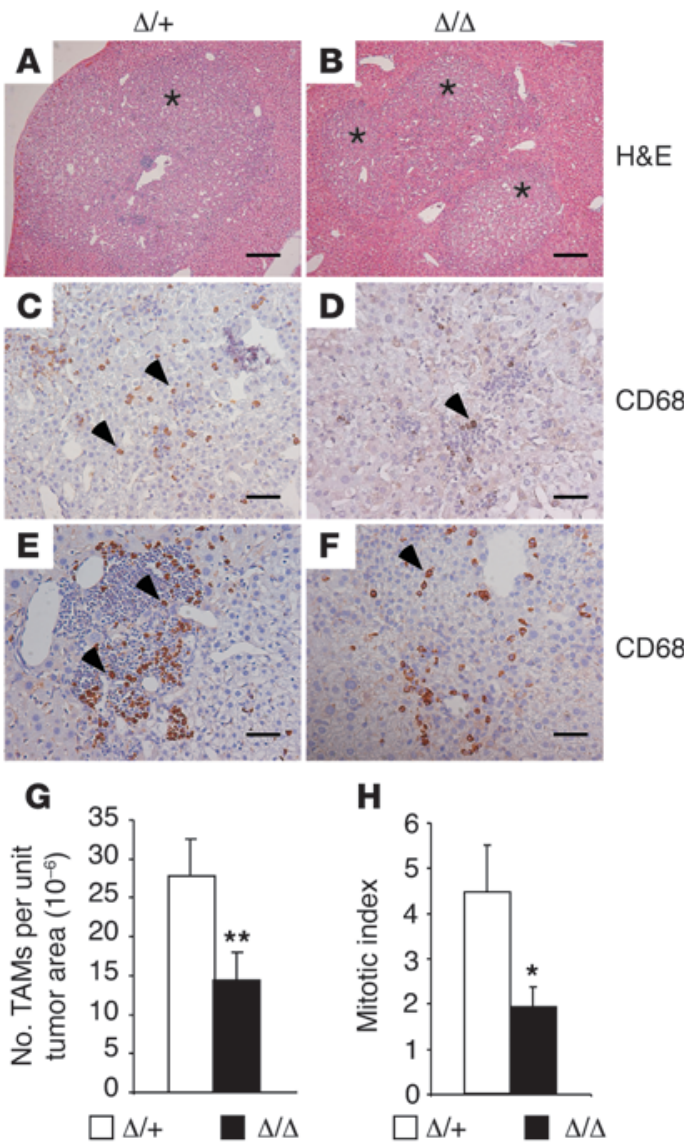

Compromised response of Hif $2 a^{\Delta / \Delta}$ mice in additional acute inflammation models. Two additional experiments were performed to further characterize the importance of HIF- $2 \alpha$ in mediating acute inflammatory responses in vivo. First we induced acute cutaneous inflammation $(73,74)$ by painting ear skin with the TPA. After 24 hours, ears were harvested and analyzed for edema and leukocyte infiltration. Edema was similar in the two genotypes, as revealed by equivalent increases in ear weight after TPA treatment $(43.59 \% \pm 10.46 \%$ in Hif $2 a^{\Delta / \Delta}$ vs. $37.71 \% \pm 11.52 \%$ in Hif $\left.2 a^{\Delta /+}, n=5\right)$. However, the number of leukocytes infiltrating TPA-treated ears was significantly reduced in Hif $2 a^{\Delta / \Delta}$ mice compared with their littermate controls $(75.9 \pm 14.8$ in Hif $2 a^{\Delta / \Delta}$ mice vs. $137.8 \pm 11.6$ in Hif $2 a^{\Delta /+}$ mice, $n=3, P=0.03$ ) (Figure 6, A-D and G). These cells were confirmed to be neutrophils based on Gr-1 staining (Figure 6, E-G), suggesting that neutrophil recruitment toward inflammation sites is affected. This is probably due to reduced production of neutrophil chemotactic factors by the local resident macrophages lacking HIF- $2 \alpha$ expression, as HIF- $2 \alpha$ is not expressed detectably in neutrophils (see above).

In the second experiment, we injected mice i.p. with thioglycollate (TG) to induce peritoneal inflammation. TG recruits large numbers of macrophages from the circulation to the peritoneal cavity $(75,76)$. Five days following TG treatment, peritoneal exudates cells were collected and grown in M-CSF-containing medium for 3 days, and the number of inflammatory macrophages was determined. As shown in Figure $6 \mathrm{H}, \mathrm{Hif} 2 \mathrm{a}^{\Delta / \Delta}$ mice recruited approximately $45 \%$ fewer macrophages compared with Hif $2 a^{\Delta / \Delta}$ mice $(n=5, P=0.0005)$. These results confirm that HIF- $2 \alpha$ deficiency impairs the ability of macrophages to respond and migrate to sites of inflammation in vivo.

\section{Figure 7}

Decreased TAM infiltration in murine HCC when macrophage HIF-2 $\alpha$ is absent. (A and B) Representative H\&E images of liver tissue containing tumor areas. Scale bars: $200 \mu \mathrm{m}$. (C-F) HCC samples were stained with the pan-macrophage marker $\mathrm{CD68}$, and positively stained brown cells were identified as infiltrating TAMs. Two representative images per genotype are shown. Scale bars: $50 \mu \mathrm{m}$. (G) TAM recruitment in control and myeloid Hif2a-deficient mice was determined under highpower $(\times 20)$ fields and normalized to the units of tumor area $(n=15$, $\left.{ }^{* \star} P=0.0017\right)$. (H) Mitotic figures of tumor cells were counted per 10 high-power $(\times 40)$ fields, and mitotic indices were determined $\left({ }^{*} P<0.05\right)$. Asterisks in A and $\mathbf{B}$ indicate tumor area. Arrowheads in C, D, E, and $\mathbf{F}$ indicate $\mathrm{CD}^{+} 8^{+} \mathrm{TAMs}$.

Myeloid HIF-2 $\alpha$ is required for autochthonous liver tumor progression. Given that HIF- $2 \alpha$ is highly expressed in TAMs in a variety of human cancers and increased TAM HIF- $2 \alpha$ levels are correlated with poor patient prognosis $(38,77,78)$, we wished to determine the role of HIF- $2 \alpha$ in TAM migration and function using genetic means. We therefore induced two independent autochthonous tumor types in mice lacking myeloid HIF-2 $\alpha$. The first tumor model employed diethylnitrosamine (DEN) to induce hepatocellular carcinoma (HCC), which is known to be modulated by myeloid cells and inflammatory cytokines (79-81). Hif $2 a^{\Delta /+}$ and Hif $2 a^{\Delta / \Delta}$ mice were injected with DEN at 2 weeks of age as described previously (79). Livers from male mice were then harvested after 9 months, by which time tumors typically developed. Liver histology is shown in Figure 7, A and B. Immunohistochemistry was performed to detect CD68-expressing TAMs. The number of TAMs recruited to tumors was markedly reduced in mutant mice compared with controls $\left(1.43 \times 10^{-5} \pm 3.6 \times 10^{-6} /\right.$ unit tumor area in Hif $2 a^{\Delta / \Delta}$ mice compared with $2.78 \times 10^{-5} \pm 4.7 \times 10^{-6} /$ unit tumor area in control mice, $n=15, P=0.0017$ ) (Figure $7, \mathrm{C}-\mathrm{G}$ ). Reduced TAM numbers were observed in all regions of the tumor, including those with dense leukocyte infiltration (Figure 7, E and F). This result suggests that macrophage recruitment into autochthonous HCCs is dependent on HIF- $2 \alpha$ expression.

Reduced TAM migration/invasion did not affect HCC number, size, or tumor vessel density in mutant livers (Supplemental Table 1). However, decreased TAM numbers correlated with delayed tumor progression, as Hif- $2 \alpha^{\Delta / \Delta}$ mice exhibited reduced incidence of high-grade (i.e., grade 3 ) tumors compared with control mice $\left(18 \%\right.$ in Hif $2 a^{\Delta / \Delta}$ mice $[n=22]$ vs. $30 \%$ in controls $\left.[n=27]\right)$. Also, tumor cell mitotic indices were significantly compromised in mutant HCCs compared with controls $\left(1.9 \pm 0.45\right.$ in Hif $2 a^{\Delta / \Delta}$ livers $[n=22]$ vs. $4.4 \pm 1.05$ in controls $[n=27], P=0.045)$ (Figure $7 \mathrm{H}$ ), although surprisingly, this effect did not manifest as differences in overall tumor growth. This may be due to the inherent variability of the model, or off-setting effects on tumor cell survival. In any event, the HCC study further supports a role for HIF- $2 \alpha$ in regulating TAM infiltration, consequently influencing tumor phenotypes including proliferation and progression.

Myeloid HIF-2 $\alpha$ is also required for the development of murine colitisassociated cancer. Given the somewhat subtle effects observed in the HCC model, we tested the role of HIF- $2 \alpha$-deficient TAMs in an independent inflammatory murine colitis-associated cancer (CAC) model. In humans, inflammatory bowel diseases, such as ulcerative colitis, are prominent risk factors for developing colorectal cancer $(82,83)$. Moreover, inflammatory components, particularly macrophages, play a crucial role in promoting progression of CAC 

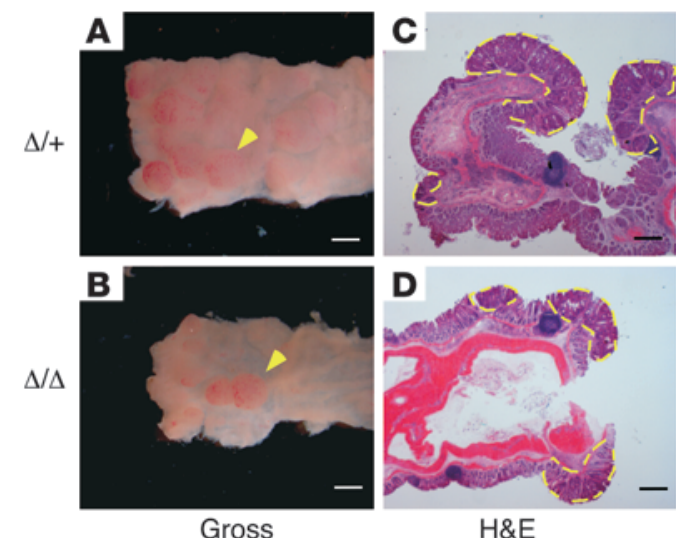

F
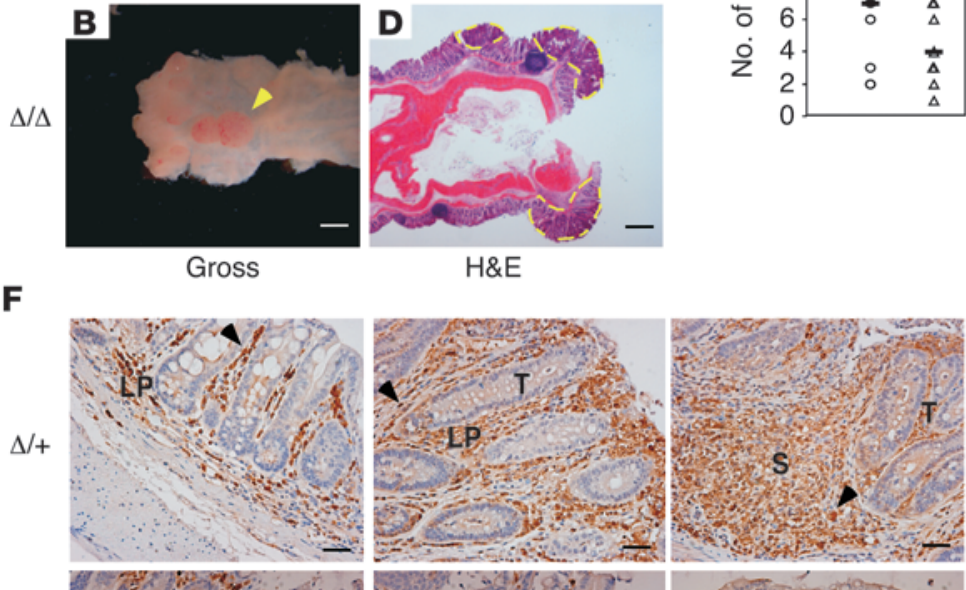

$\Delta / \Delta$

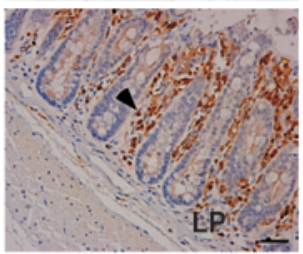

Colon tissue adjacent to tumor

G

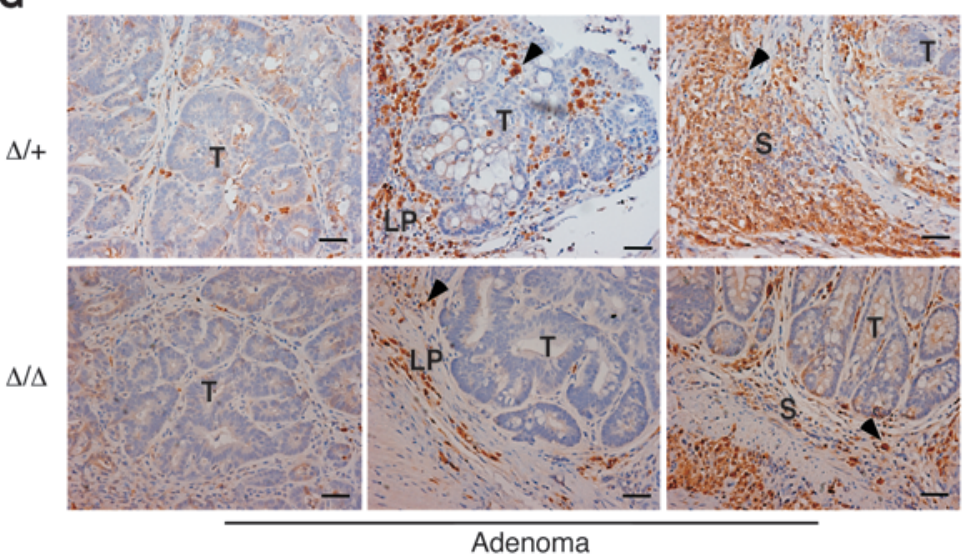

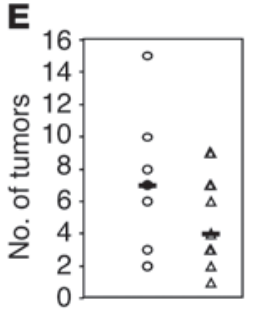

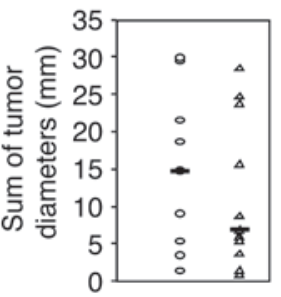

○: $\Delta /+$

$\Delta: \Delta / \Delta$

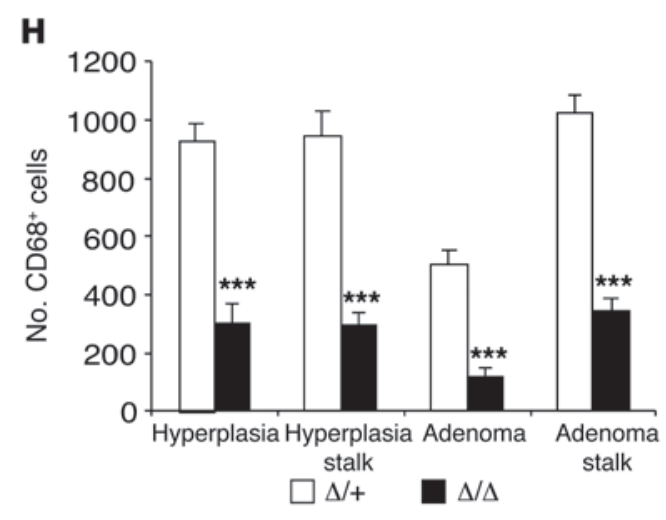

I

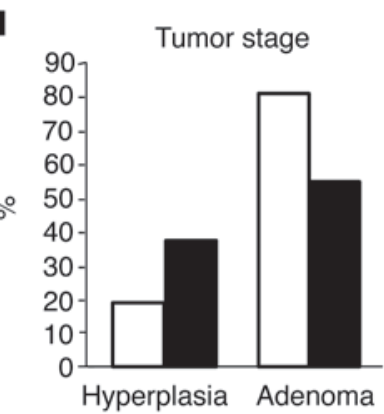

J Mitosis

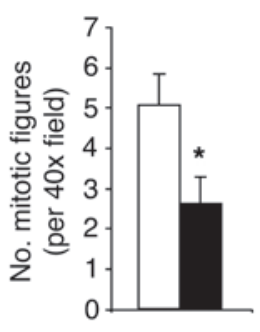

$\Delta / \Delta$

\section{Figure 8}

Loss of TAM HIF-2 $\alpha$ leads to reduced tumor burden and progression in murine CAC. (A and B) Control $(\Delta /+)$ and mutant $(\Delta / \Delta)$ mice were induced to form CAC for 14 weeks, and gross pictures of tumors in the colon and rectum are shown. Arrowheads indicate macroscopic lesions. Scale bars: $3.125 \mathrm{~mm}$. (C and D) Colon sections were stained with H\&E; neoplastic lesions are outlined with yellow dashes. Scale bars: $3.125 \mathrm{~mm}$. (E) Top panel shows total number of CAC tumors in both control and mutant cohorts. Bottom panel shows total tumor size (represented as sum of diameters of all tumors). Bars indicate median value of each group. (F) CD68 immunostaining of CAC colons. Left: Distribution of CD68 ${ }^{+}$macrophages (brown) in normal colon tissue adjacent to tumors. Middle: CD68+ TAM infiltration to the surrounding lamina propria (LP) of hyperplasia. Right: TAM recruitment to LP at stalk area of hyperplasia. Scale bars: $20 \mu \mathrm{m}$. (G) CD68 immunostaining of CAC adenomas. Left: Limited TAM infiltration to the center of large lesions. Middle: TAM recruitment to small lesions. Right: TAMs presented in LP at stalk area. Scale bars: $20 \mu \mathrm{m}$. (H) Quantification of CD68+ cells. (I) Quantification of tumor stages of CAC. Percentages of hyperplasia and adenoma within control $(\Delta /+)$ and mutant $(\Delta / \Delta)$ groups are shown. (J) Histopathological analysis of mitosis of adenoma tumor cells. Arrowheads in F and $\mathbf{G}$ indicate CD68 ${ }^{+}$TAMs. $\mathrm{T}$, tumor area; $\mathrm{S}$, stalk. ${ }^{\star} P<0.05,{ }^{\star \star \star} P<0.001$. 
A

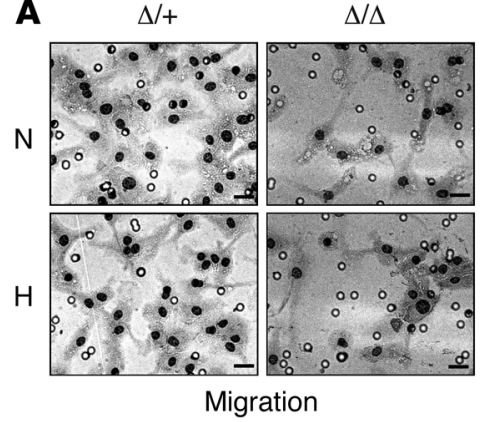

B

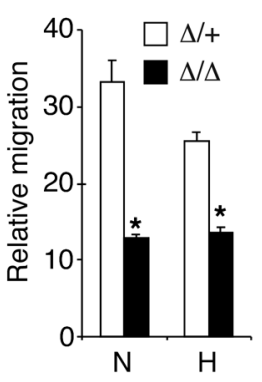

C

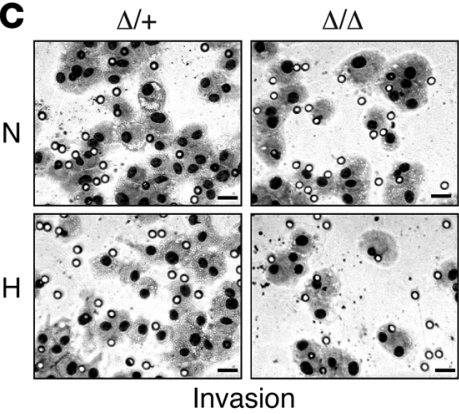

D

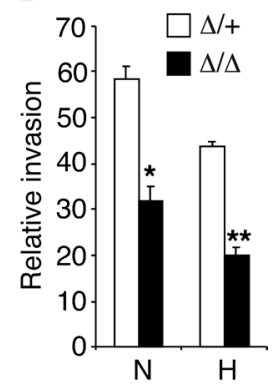

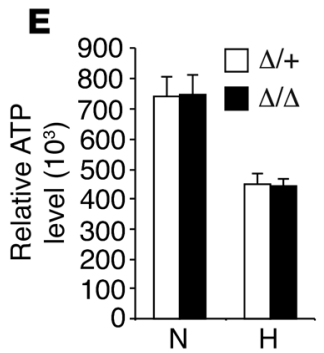
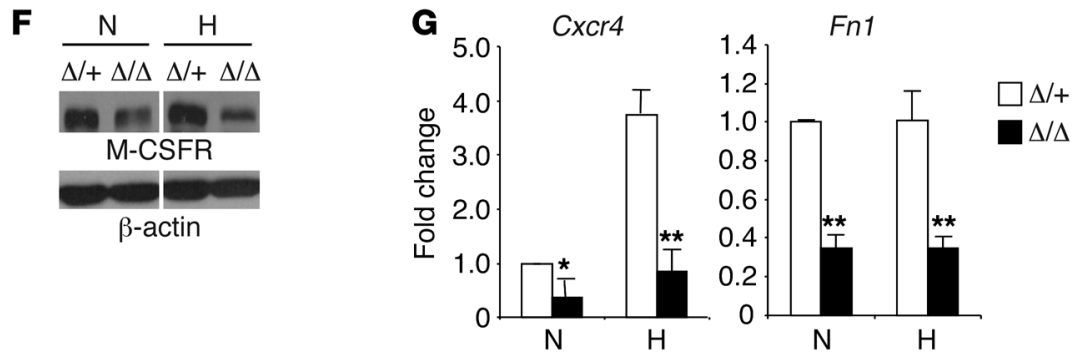

\section{Figure 9}

Reduced migration and invasion, but normal ATP production in HIF-2 $\alpha$-deficient macrophages. (A) BMDMs were exposed to normoxia or hypoxia for 16 hours, and their in vitro migration capacity toward the chemoattractant M-CSF was determined by employing a barrier PET membrane (8 $\mu$ m; BD Biosciences). Representative images are shown. Scale bars: $20 \mu \mathrm{m}$. (B) Quantification of migrated macrophages. Representative data are shown from $n=4$ mice $\left({ }^{*} P<0.05\right)$. (C) Invasion was tested as described above for migration, except that the barrier PET membrane was coated with Matrigel basement membrane matrix (BD Biosciences). Representative images are shown. Scale bars: $20 \mu \mathrm{m}$. (D) Quantification of macrophages that invaded through the Matrigel. Representative data from $n=3$ mice are shown $\left({ }^{*} P<0.05,{ }^{* *} P<0.01\right)$. (E) BMDMs were exposed to normoxia or hypoxia for 20 hours, and cellular ATP levels were determined using the ApoGlow Assay kit. Representative data from at least 3 independent experiments are shown. (F) Expression of M-CSFR under normoxia and hypoxia was determined by Western blotting. Representative data from 3 independent experiments are shown. Lanes were run on the same gel but were noncontiguous (white lines). (G) Cxcr4 and Fn1 expression in normoxic and hypoxic BMDMs was evaluated by QRT-PCR. Representative data from at least 3 independent experiments are shown $\left({ }^{*} P<0.05,{ }^{* *} P<0.01\right)$. N, normoxia $\left(21 \% \mathrm{O}_{2}\right) ; \mathrm{H}$, hypoxia $\left(0.5 \% \mathrm{O}_{2}\right)$.

(84-86). To induce CAC, a single intraperitoneal injection of the procarcinogen azoxymethane (AOM) was administered to mice, followed by 3 cycles of dextran sulfate sodium (DSS) treatment, which results in chronic ulcerative colitis (87). Fourteen weeks later, mice were sacrificed for tumor analysis. At this stage, colon lesions appeared to be either hyperplasia or adenoma and mostly developed in the distal colon and rectum (Figure 8, A-D). Macroscopic tumors were counted across the whole colon and rectum, and tumor size was measured. As shown in Figure 8E, mutant mice displayed trends of fewer lesions and reduced tumor burden, as represented by the sum of tumor sizes (Hif $2 a^{\Delta /+}, n=9 ;$ Hif $2 a^{\Delta / \Delta}$, $n=11)$. These differences did not reach statistical significance. Nevertheless, as the statistical tests are underpowered $(17 \%$ for lesion numbers and $10 \%$ for tumor burden), these likely represent type II (or $\beta$ ) errors. Studies on larger cohorts of mice might validate our interpretation of these results.

We next evaluated TAM infiltration by CD68 immunostaining. Hyperplasia development was accompanied by intensive recruitment of macrophages to the surrounding lamina propria (Figure $8 \mathrm{~F}$ ), as previously reported $(88,89)$. In adenomas, TAM infiltration into the center of large lesions was limited compared with the margins adjacent to lamina propria, whereas small lesions showed recruitment of $\mathrm{CD} 68^{+}$macrophages in both the center and the margin (Figure 8G). Of note, large number of macrophages accumulated in the lamina propria located at the stalk of both hyperplastic tissues and adenomas (Figure 8, F and G). Interestingly, $\mathrm{CD}^{+} 8^{+}$cell numbers were dramatically reduced (by approximately $70 \%, n=5, P<0.001$ ) in Hif $2 a^{\Delta / \Delta}$ mice compared with control Hif2 $a^{\Delta /+}$ animals, regardless of tumor area and stage (Figure $8 \mathrm{H}$ ). These results support findings from the HCC experiment indicating that macrophage HIF- $2 \alpha$ is critical for TAM recruitment to the tumor microenvironment.

In addition, mutant mice displayed a trend toward a reduced percentage of high-grade tumors (e.g., adenoma) and an increased percentage of lower-grade tumors (e.g., hyperplasia) (Figure 8I). These differences did not achieve statistical significance, and larger numbers of animals are required for further analysis. Interestingly, as noted in the HCC model, tumor cells of mutant mice displayed significantly reduced mitosis, although Hif2a deletion was restricted to macrophages (Figure 8J). This effect may be due to decreased expression of pro-growth factors such as TNF- $\alpha$ and IL- 6 in mutant tumors $(90,91)$ resulting from reduced TAM numbers and/or Hif2a deficiency in these cells. It is striking that deleting Hif $2 a$ in macrophages leads to decreased numbers of TAMs, reduced mitotic indices, and compromised progression in two unrelated inflammationassociated autochthonous tumor models. We therefore conclude that HIF- $2 \alpha$ is required for efficient TAM infiltration into tumors, which in turn reinforces disease progression.

Hif $2 a^{\Delta / \Delta}$ macrophages exhibit reduced migration, invasion, and chemotactic receptor expression in vitro. To determine whether the migration defects observed in the acute inflammation and tumor models represent myeloid cell-intrinsic properties, we isolated BMDMs and examined HIF- $2 \alpha$ effects on macrophage migra- 


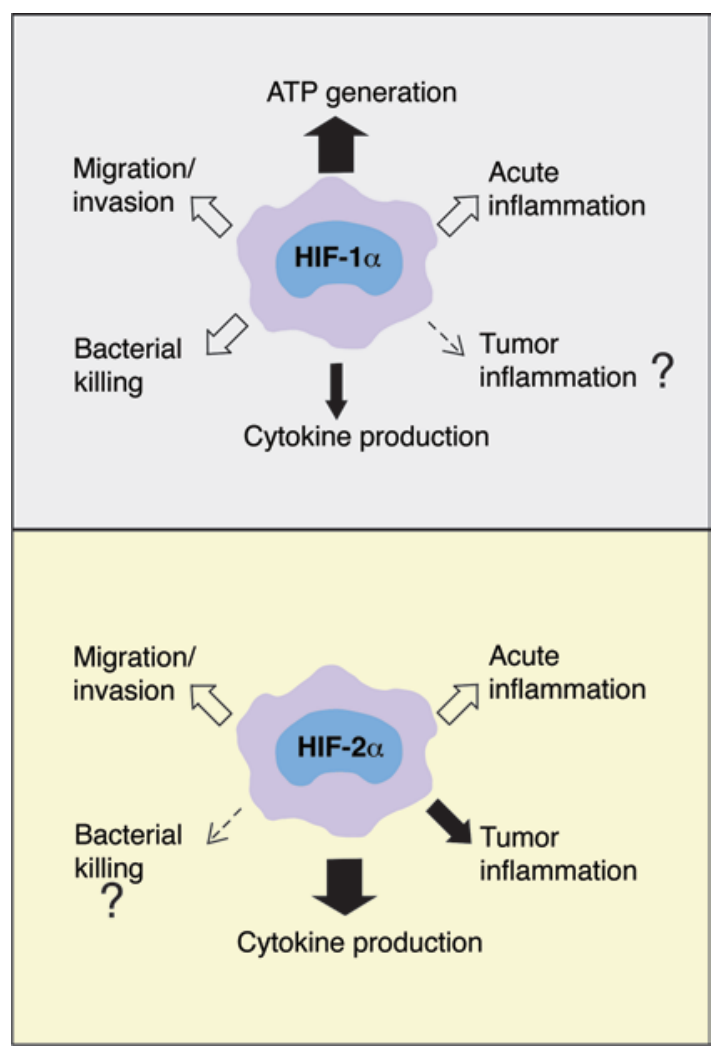

tion in vitro. Briefly, BMDMs were exposed to normoxia or hypoxia for 16 hours, and their migration and invasion toward the chemoattractant M-CSF was measured by using Boyden chambers $(92,93)$. Interestingly, HIF-2 $\alpha$ deficiency compromised both migratory and invasive properties of macrophages to approximately $50 \%$ of that of Hif $2 a^{\Delta /+}$ BMDMs (Figure 9, A-D). As migration is a highly ATP-dependent process (39), we compared intracellular ATP levels, which were similar in mutant and control macrophages under both normoxic and hypoxic conditions (Figure 9E). We next measured M-CSFR levels in macrophages. Western blotting showed reduced M-CSFR protein levels in Hif $2 a^{\Delta / \Delta}$ BMDMs compared with controls (Figure 9F). These results suggest that expression of the chemotactic receptor M-CSFR, rather than the ATP depletion observed in Hif1 $a^{\Delta / \Delta}$ deficient macrophages (39), underlies the mechanism for defective migration and invasion in Hif $2 a^{\Delta / \Delta}$ macrophages, at least in part.

CXCR4, the receptor for the chemokine CXCL12 (also known as SDF-1), also plays an important role in facilitating macrophage migration in vivo $(94,95)$. Importantly, Cxcr4 expression was significantly decreased (by $65 \%, n=4, P=0.0358$ ) in Hif $2 a^{\Delta / \Delta}$ macrophages compared with controls, even under normoxic conditions (Figure 9G), indicating that basal HIF-2 $\alpha$ levels contribute to Cxcr4 expression. We also observed a 4-fold hypoxic induction of Cxcr4 expression in control BMDMs, which was profoundly reduced (by $80 \%, n=4, P=0.00433$ ) in Hif $2 a^{\Delta / \Delta}$ BMDMs, suggesting that CXCR4 is regulated by HIF- $2 \alpha$. As in vivo monocyte and neutrophil transmigration from the circulation to tissues involves adhesion to endothelial cells, we assessed expression of adhesion molecules such as integrins $\beta 1, \beta 2, \beta 3, \alpha M, \alpha 4$, and $\alpha 5$, as well as intercellular adhesion molecule- 1 and -2 (ICAM-1 and -2), CD31 (PECAM-1), and F4/80 using flow cytometry and

\section{Figure 10}

Model illustrating the roles of HIF- $1 \alpha$ and HIF-2 $\alpha$ in macrophages. HIF- $1 \alpha$ exclusively regulates ATP generation and contributes to cytokine production, as well as macrophage function in acute inflammation, migration/invasion, and bacterial killing. HIF-2 $\alpha$ also regulates acute inflammation and migration/invasion, but not ATP production in macrophages. Additionally, HIF-2 $\alpha$ controls tumor inflammation and appears to play a bigger role in cytokine production than HIF-1 $\alpha$. Further investigation is needed to determine whether HIF- $2 \alpha$ is required for macrophage bactericidal activity.

RNA analysis. We detected no differences in integrin or adhesion molecule expression levels between Hif $2 a^{\Delta / \Delta}$ and control macrophages (data not shown); however, possible differences in affinity or avidity would not be detected in these assays. To evaluate these possibilities, we tested control and mutant macrophages in a variety of adhesion assays, but no differences were observed between Hif $2 a^{\Delta /+}$ and Hif $2 a^{\Delta / \Delta}$ cells (data not shown). Macrophages also secrete fibronectin-1 (FN1), which mediates a wide variety of cellular interactions with the ECM and plays important roles in cell migration. FN1 promotes cell migration by directly binding to cell surface integrin receptors and other biologically important molecules such as heparin and fibrin (96). We determined that Fn1 levels were reduced in mutant macrophages under both normoxia (65\% reduction compared with controls, $n=4, P=0.0022$; Figure $9 \mathrm{G}$ ) and hypoxia (66\% reduction compared with controls, $n=4, P=0.0091$ ), consistent with observed migration defects in Hif $2 \alpha^{\Delta / \Delta}$ BMDMs under these conditions. These data indicate that HIF- $2 \alpha$ controls macrophage migration, in part by regulating the expression of cytokine receptor M-CSFR and chemokine receptor CXCR4 and the extracellular protein FN1.

\section{Discussion}

A complex picture exists regarding the precise roles of the two HIF- $\alpha$ isoforms in regulating target gene expression and mediating disease progression. Whereas HIF- $1 \alpha$ promotes the growth of breast and colon cancers $(97,98)$, HIF- $2 \alpha$ is the predominant hypoxic effector in the progression of clear cell renal cell carcinomas (ccRCC) and non-small cell lung cancers (NSCLCs) (99-102). These data, as well as distinct phenotypes of $\mathrm{Hifla}^{-/-}$and $\mathrm{Hif2 \textrm {a } ^ { - / - }}$ mice, indicate that the two HIF- $\alpha$ subunits provide nonredundant functions, and their relative roles are likely to differ depending on cell type. Both HIF- $1 \alpha$ and HIF- $2 \alpha$ are stabilized in hypoxic macrophages in vitro $(36,37)$. Talks et al. showed that HIF- $2 \alpha$ protein accumulates at high levels in TAMs detected in various human cancers (38). Furthermore, HIF- $2 \alpha$ overexpression in normoxic human macrophages leads to enhanced transcription of proangiogenic genes, such as VEGF, IL8, platelet-derived growth factor $\beta$ (PDGFB), and angiopoietin-like 4 (ANGPTL4). Of note, HIF-1 $\alpha$ had no effect in these analyses, suggesting that HIF- $2 \alpha$ plays an important and distinct role in macrophage adaptation to low $\mathrm{O}_{2}(103)$. Previous studies revealed an important role for myeloid HIF- $1 \alpha$ in mediating macrophage-dependent inflammatory and antibacterial activities (39-41). It was therefore critical to genetically define the function of HIF- $2 \alpha$ in macrophage-mediated responses such as in acute inflammation and the tumor microenvironment.

Using a murine model of endotoxemia, we demonstrated that HIF- $2 \alpha$ ablation in macrophages profoundly disrupts the balance between proinflammatory and antiinflammatory responses, resulting in an immunosuppressive milieu in LPS-treated Hif $2 a^{\Delta / \Delta}$ 
mice. Furthermore, abnormal cytokine production correlates with fewer systemic toxic effects, as evidenced by improved cardiac function and survival in LPS-treated Hif $2 a^{\Delta / \Delta}$ mice. Together with reduced neutrophil infiltration during the acute skin inflammation and compromised peritoneal macrophage recruitment in Hif $2 a^{\Delta / \Delta}$ mice, the results indicate that macrophage HIF- $2 \alpha$ plays an important role in regulating inflammatory responses during acute inflammatory conditions, a function shared with HIF-1 $\alpha$ (39). However, unlike HIF-1 $\alpha$ (40), the regulation of inflammation by HIF- $2 \alpha$ does not involve NO production. Furthermore, HIF- $2 \alpha$ does not regulate the expression of costimulatory molecules. Interestingly, our evidence suggests that HIF- $2 \alpha$ plays a distinct role in regulating proinflammatory cytokine expression, in part by direct binding to the promoters of cytokine genes, as demonstrated for IL6 (Figure 5). Our results suggest that HIF-2 $\alpha$ serves as a critical transcriptional regulator in macrophages under circumstances of $\mathrm{O}_{2}$ deprivation, amplifying cytokine expression and other inflammatory responses such as leukocyte infiltration. These findings emphasize the underappreciated impact of hypoxic responses on innate immunity. Therefore, the HIF- $2 \alpha$ pathway could be exploited as a novel target for designing interventional strategies for treating inflammatory diseases.

Previous clinical studies showed that high TAM HIF-2 $\alpha$ levels correlate with increased tumor grade and tumor vascularity $(38,77)$, and increased numbers of HIF- $2 \alpha$-expressing TAMs are associated with poor prognosis and local recurrence (78). To characterize the role of HIF- $2 \alpha$ in TAMs, we induced HCC and CAC in mice lacking myeloid HIF-2 $\alpha$ expression. In both models, we found that HIF-2 $\alpha$-deficient TAMs migrate into tumors less efficiently. As macrophages are a major component of cellular infiltrates and are known to promote inflammation-associated cancers, we anticipated that decreased TAM numbers would negatively affect tumorigenesis. Indeed, we observed compromised disease progression in mutant mice, although these effects were more striking in the CAC model than in the HCC model. Our study suggests that HIF- $2 \alpha$ expression in hypoxic TAMs can indirectly impact tumor development and progression in these models. It would be interesting to compare the activity of HIF- $1 \alpha$ in these models using mice carrying a Hifla conditional allele in future work.

As stated above, HIF- $2 \alpha$ regulates macrophage migration based on in vivo models of inflammation and cancer. This was confirmed to be a cell-intrinsic property, as Hif $2 a^{\Delta / \Delta}$ macrophages exhibited reduced migration and invasion in vitro. Interestingly, our results indicate that reduced migration derives, at least in part, from decreased expression of the cytokine receptor M-CSFR, chemokine receptor CXCR4, and the extracellular molecule FN1 in Hif $2 a^{\Delta / \Delta}$ macrophages.

Overall, loss of macrophage HIF- $1 \alpha$ results in reduced migration/invasion, acute inflammation, and bacterial killing, although the degree to which this is a secondary consequence of reduced macrophage ATP levels is not clear $(39,40)$. Here we report that HIF- $2 \alpha$-deficient macrophages display compromised inflammatory and migratory/invasive activity but that intracellular ATP levels are maintained (Figure 9). These data are consistent with previous studies demonstrating an exclusive role for HIF-1 $\alpha$ (and not HIF-2 $\alpha$ ) in promoting glycolysis in hypoxic cells (27). Interestingly, HIF- $2 \alpha$ is essential for proinflammatory cytokine expression, as the cytokine defect manifested in myeloid HIF- $2 \alpha$-deficient endotoxemic mice is considerably more pronounced than that observed in septic HIF-1 $\alpha$-deficient mice (Figure 2 and ref. 41). Collectively, the division of labor between the two HIF- $\alpha$ subunits appears to be elaborately maintained by their regulation of overlapping, but also distinct, functions in macrophages (Figure 10).

It was reported recently that macrophage HIF- $1 \alpha$ and HIF- $2 \alpha$ activity can be differentially regulated by cytokine stimuli (104). Th1 cytokines (such as IFN- $\gamma$ ) induce HIF-1 $\alpha$ expression, whereas Th2 cytokines (such as IL-4) promote HIF- $2 \alpha$ expression. To evaluate the role of HIF- $2 \alpha$ in M2 polarization, we treated BMDMs with the Th2 cytokine IL-4 and examined a variety of macrophage responses. Induction of arginase activity, which regulates NO synthesis and promotes tissue repair, is a hallmark of the M2 phenotype. Although IL-4 or hypoxia treatment alone triggered dramatic increases in arginase activity, this did not require HIF- $2 \alpha$ (Supplemental Figure 4A). Similarly, HIF-2 $\alpha$ was not required for cell surface mannose receptor expression, another hallmark of M2 activation (Supplemental Figure 4B). Interestingly, FN1 expression downstream of M2 activation was dependent on HIF- $2 \alpha$ under both normoxic and hypoxic conditions (Supplemental Figure $4 \mathrm{C})$. These results demonstrated that HIF- $2 \alpha$ mediates some, but not all, M2 responses.

It is interesting to note that genetic modifiers of the myeloidspecific Hif $2 a^{\Delta / \Delta}$ phenotypes reported here appeared to be segregating in our mice, which were maintained on a mixed $129 / \mathrm{Sv}$ $\times$ C57BL/6 genetic background. For example, consistent hypoxic phenotypes (shown in Figure 1D) were observed in approximately $70 \%$ of Hif $2 a^{\Delta / \Delta}$ mice, whereas macrophages from the remaining $30 \%$ of mutant mice did not reveal clear abnormalities. However, we observed that when HIF- $2 \alpha$-deficient macrophages from a specific mouse displayed hypoxic phenotypes in a given assay, they also displayed hypoxic phenotypes in all other analyses. Furthermore, the magnitude of these responses was highly reproducible between mice. Data from mice exhibiting consistent hypoxic phenotypes ( $70 \%$ of all mutants analyzed) are therefore presented, unless stated otherwise. This finding is consistent with multiple previous reports noting the effects of modifier loci segregating in mixed $129 / \mathrm{Sv} \times \mathrm{C} 57 \mathrm{BL} / 6$ genetic backgrounds that alter the penetrance of HIF- $2 \alpha$ mutant phenotypes. For example, Compernolle et al. showed that $50 \%$ of homozygous Hif $2 a$-deficient embryos in a mixed $129 / \mathrm{Sv} \times \mathrm{C} 57 \mathrm{BL} / 6$ genetic background died of bradycardia as shown by Tian et al. (105), whereas the remainder died perinatally from defects in lung maturation (106). In another report, independently generated Hif2 $\mathrm{a}^{-/-}$embryos died between E9.5 and E13.5; approximately $50 \%$ of the Hif $2 \mathrm{a}^{-/-}$embryos displayed yolk sac and embryonic vascular remodeling defects, whereas the others appeared to succumb to bradycardia (107). Collectively, these results suggest that HIF- $2 \alpha$ is particularly susceptible to genetic modifier effects. We are currently backcrossing both the Hif $2 a$ conditional and LysM-Cre alleles into a pure C57BL/6 background to investigate this possibility.

Two additional observations suggest that the effects of HIF- $2 \alpha$ on macrophage function may be more pronounced than those reported in our experiments, in which heterozygous (Hif $2 a^{\Delta /+}$ ) BMDMs were used as controls. First, we found that IL- 6 production in M1-stimulated wild-type (Hif2 $\mathrm{a}^{+/+}$) BMDMs was greater than that in heterozygous (Hif2 $a^{\Delta /+}$ ) BMDMs (Supplemental Figure 5). Second, we observed that some phenotypes, such as M1 cytokine responses (Figure 4A) and migration and invasion (Figure 9, A-D), were evident in Hif $2 a^{\Delta / \Delta}$ BMDMs even under normoxic conditions, suggesting that low basal levels of HIF- $2 \alpha$ (Figure 1C) contribute to their biological properties. Together, these data further support 
our conclusion that HIF- $2 \alpha$ tightly regulates macrophage functions and is an important immune regulator in these cells.

Myeloid cells appear to adapt in interesting ways to low $\mathrm{O}_{2}$ conditions encountered at sites of inflammation, and the relative importance of individual HIFs in these responses is receiving increased attention. Our study extends the results of Cramer and colleagues (39) by demonstrating that hypoxia promotes multiple macrophage functions through independent activities of HIF- $1 \alpha$ and HIF- $2 \alpha$. Hypoxia also contributes to a highly inflammatory state of macrophages, as evidenced by elevated levels of cytokines (Figure 4A). Further investigation is required to elucidate the differential activities of HIF- $1 \alpha$ and HIF- $2 \alpha$ in other myeloid lineages. For example, HIF-1 $\alpha$ has been shown to mediate hypoxic inhibition of neutrophil apoptosis (108), but HIF-2 $\alpha$ is unlikely to play a role in neutrophils, since it is not expressed in this lineage. In addition, a recent report has revealed that hypoxia and HIF- $1 \alpha$ modulate DC maturation, activation, and inflammatory responses (109), although a role for HIF-2 $\alpha$ in these cells has not yet been demonstrated. Elucidating the modulation of macrophages and other innate immune cells by hypoxia and the HIFs may ultimately provide new molecular targets through which inflammatory responses can be manipulated in pathological conditions.

\section{Methods}

Mice. The Hif2a conditional allele (29) on a mixed 129/Sv $\times$ C57BL/ 6 background was crossed with the LysM-Cre allele (42) to achieve myeloid-specific Hif2a conditional knockout mice. Genotyping using Southern blotting and PCR techniques was performed according to Gruber et al. (29). All procedures involving mice were performed in accordance with NIH guidelines and were approved by the University of Pennsylvania IACUC.

Stimulation of BMDMs and in vitro assays. Preparation of mouse BMDMs was performed as previously described $(39,40)$. For hypoxia induction experiments, the mouse BMDMs were treated under either normoxia $\left(21 \% \mathrm{O}_{2}\right)$ or hypoxia $\left(0.5 \% \mathrm{O}_{2}\right)$ for most experiments, or $3 \% \mathrm{O}_{2}$ for $\mathrm{NO}$ experiments, for the times indicated. For M1 stimulation, BMDMs were first primed with $0.1 \mathrm{ng} / \mathrm{ml}$ IFN- $\gamma$ for 4 hours at normoxia and then treated with various concentrations of LPS plus IFN- $\gamma$ as indicated. NO levels were determined using the Griess assay (Promega). ELISA was performed per the manufacturer's instructions. ELISA kits for IL-12 p70, TNF- $\alpha$, IL-6, IFN- $\gamma$, and IL-10 were purchased from eBioscience; the ELISA kit for IL- $1 \beta$ was obtained from R\&D Systems. Surface expression of MHC class II, CD80, and CD86 molecules was evaluated by flow cytometry. mRNA and protein analysis was performed according to Gruber et al. (29). NF-kB DNA binding assays were performed according to protocols described in the TransAM NFкB family kit (Active Motif). For M2 stimulation, BMDMs were treated with recombinant IL-4 at the concentrations indicated. Arginase activity was measured according to an established method (110). Mannose receptor expression was determined by flow cytometry. FN1 expression was evaluated by QRT-PCR.

Neutrophils and DCs. Bone marrow-derived neutrophils were isolated as previously described (111). MPRO cells were induced to differentiate with addition of all-trans retinoic acid $(10 \mu \mathrm{M})$. After 3 days, cells were preincubated under normoxia or hypoxia $\left(0.5 \% \mathrm{O}_{2}\right)$ for 4 hours and treated with TPA $(100 \mathrm{ng} / \mathrm{ml})$ for 15 minutes. DCs were prepared from bone marrow as described previously (112). Bone marrow progenitors were differentiated for 8 days in the presence of GM-CSF $(20 \mathrm{ng} / \mathrm{ml})$ and harvested, and DCs were enriched by using the EasySep CD11c-PE positive selection kit (StemCell Technologies). DCs were activated with LPS $(10 \mathrm{ng} / \mathrm{ml})$ for 24 hours under normoxia and hypoxia $\left(0.5 \% \mathrm{O}_{2}\right)$. Expression of HIF isoforms was evaluated by QRT-PCR and Western blotting.
In vivo inflammation experiments. LPS-induced endotoxemia was achieved essentially as described previously (41). Female mice were used for the survival study. Serum cytokine levels were measured by ELISAs 4 hours following LPS $(15 \mathrm{mg} / \mathrm{kg})$ treatment. Echocardiography was recorded 6 hours following LPS $(10 \mathrm{mg} / \mathrm{kg})$ injection. For IL-10 blocking experiments, control and mutant mice were injected i.p. with $150 \mu \mathrm{g}$ rat anti-mouse IL-10 Abs (clone 2A5, Thermo Scientific) or isotype control rat IgG1 (BD Biosciences - Pharmingen) 2 hours prior to LPS $(10 \mathrm{mg} / \mathrm{kg})$ induction of endotoxemia. TPA-induced ear inflammation was accomplished according to ref. 39. Skin tissues were harvested at 24 hours following TPA treatment, and sections were prepared for $\mathrm{H} \& \mathrm{E}$ staining and Gr-1 immunohistochemistry. Peritoneal inflammation was induced by TG. Mice were injected i.p. with $1 \mathrm{ml}$ of $3 \% \mathrm{TG}$, and at 5 days peritoneal exudate cells were collected by sterile lavage. The cells were washed and seeded onto petri dishes with DMEM containing 30\% L929-conditioned medium (see the above recipe used for cultivating BMDMs). The cells were allowed to attach for 2 hours, and medium was changed to remove nonadherent cells. The resulting peritoneal exudate macrophages were grown at $37^{\circ} \mathrm{C}$ for 3 days before being enumerated.

Echocardiography. Transthoracic echocardiography was performed on lightly anesthetized (1\%-2\% isoflurane) mice with a high-resolution Vevo 770 micro-ultrasound system (VisualSonics). The ECG signal was obtained from the electrode pads on the mouse platform. LV wall thickness and LV internal dimensions at end-diastole and end-systole (LVIDd, LVIDs) were measured using M-mode echocardiography. LV ejection time (ET) was measured by Doppler echocardiography. LV fractional shortening $[F S=(L V I D d-L V I D s) /$ $L V I D d \times 100 \%]$ and velocity of circumferential fiber shortening $\left(V_{c f}=F S / E T\right)$ were calculated (63). The same measurements were performed before and 6 hours after LPS treatment. Mouse core temperatures were monitored with a rectal temperature probe coupled to a digital thermometer.

ChIPs. U937 cells were differentiated with TPA $(100 \mathrm{U} / \mathrm{ml})$ for 3 days to achieve maturation. These cells were then activated by $\mathrm{M} 1$ stimuli $(100 \mathrm{ng} / \mathrm{ml} \mathrm{LPS}$ plus $12 \mathrm{ng} / \mathrm{ml} \mathrm{IFN}-\gamma)$, hypoxia $\left(0.5 \% \mathrm{O}_{2}\right)$, or a combination of both. For HIF-2 $\alpha$ stabilization and IL- 6 expression experiments, U937 activation lasted for 24 hours. ChIP assays were performed using a Chromatin Immunoprecipitation Assay kit (Millipore) according to the protocol described by the manufacturer. Briefly, $1 \times 10^{7}$ cells were activated for 5 hours under various conditions and fixed with $1 \%$ formaldehyde $(7.5$ minutes for normoxic and 5 minutes for hypoxic samples). Cell nuclei were isolated, and DNA from $1.2 \mathrm{mg}$ nuclear extract was sheared to $500-1,500 \mathrm{bp}$ by sonication. The resulting fragmented chromatin was precleared with normal goat IgG (Santa Cruz Biotechnology Inc.) and protein A/agarose beads for 1 hour and divided into two ChIP reactions, i.e., HIF- $\alpha-$-specific and IgG control ChIPs. DNA was enriched by immunoprecipitation using $10 \mu \mathrm{g}$ of either the goat anti-mouse HIF- $2 \alpha$ (R\&D Systems) or goat IgG control antibodies complexed to Protein A/agarose beads. The formaldehyde crosslinks from the immunoprecipitated DNA were de-associated with heat $\left(65^{\circ} \mathrm{C}\right.$ overnight). Protein and RNA were removed by proteinase $\mathrm{K}$ and RNase A treatments. Nonenriched DNA samples were treated in a similar manner to serve as input controls. The resulting ChIP and input DNAs were subject to PCR reactions using AccuPrime GC-rich DNA polymerase (Invitrogen) and primers specific for several promoter regions of IL6 potentially bearing HRE motifs. Primers used for the $-1.6-\mathrm{kb}$ sequence were 5'-GCCTGTAAACCCAGCACTTT-3' (forward), 5'-AGCAATTCTCTTGCCTCAGC-3' (reverse); for the -1.7-kb sequence, $5^{\prime}$-CAGTGGTTCACGCCTGTAAA-3' (forward), 5'-CCCAGGTTCAAGCAATTCTC-3' (reverse); for the -2.2-kb sequence, $5^{\prime}$-GACTCATCCATCTCCAACCC-3' (forward), 5'-ACTGCCCATGACTGCTTTCT-3' (reverse).

Migration and invasion. Migration assays were performed using 24-well chambers with inserts (8- $\mu$ m pores) (catalog $353097, \mathrm{BD})$. Medium with M-CSF (in the form of 2929 conditioned medium) lacking serum was 
placed in the lower chamber, and BMDMs $\left(1 \times 10^{5}\right)$ suspended in medium without M-CSF but with serum were added in the top chamber. The plates were incubated under $21 \%$ or $0.5 \% \mathrm{O}_{2}$ for 22 hours. After migration, nonmigratory cells were removed from the top of the insert membrane using cotton swabs. The underside of each membrane was fixed and stained with the Diff Quick Stain Kit (IMEB Inc.), and the number of cells that migrated completely through the $8-\mu \mathrm{m}$ pore was determined in 4 random high-power fields ( $\times 40$ objective) for each membrane. Invasion was examined in a similar way with the addition of Matrigel coating on the insert membrane (catalog 354483, BD) (92, 93). ATP levels were determined using an ApoGlow Assay kit (Cambrex) per the manufacturer's instructions. M-CSFR expression was evaluated by Western blotting using a polyclonal anti-M-CSFR antibody (Cell Signaling Technology).

Tumor induction and study. To induce HCC, we injected 15-day-old mice and littermates (Hif $2 a^{\Delta / \Delta}$ and Hif2 $a^{\Delta /+}$ ) i.p. with $5 \mathrm{mg} / \mathrm{kg}$ DEN. Male mice were used for tumor studies. After 9 months, livers were perfused intracardially with PBS and 4\% PFA, harvested, and fixed. Livers were separated into individual lobes and paraffin embedded. Sections $(5 \mu \mathrm{m})$ containing all liver lobes were H\&E stained, and total tumor numbers were determined. HCC was graded based on multiple histological standards (grade 1: no nodules and no necrosis; grade 2: small to medium multifocal nodules and no necrosis; grade 3: large nodules that often coalesce and contain regions of necrosis). Mitotic indices were determined by counting mitotic figures per 10 high-power $(\times 40)$ fields in the nodule in a liver that contained the highest number of mitotic figures. Vascular invasion was evaluated by determining numbers of nodules or tumor cell aggregates that invade through blood vessels in a given liver. Tumor-occupied areas were determined by MetaMorph software (Molecular Devices) based on 3 fields ( $\times 20$ objective) representing the highest tumor burden. Sections were stained for $\alpha$-SMA, and vessel density was determined by counting $\alpha$-SMA ${ }^{+}$ vessels per unit tumor area. TAM density was evaluated by counting $\mathrm{CD}^{+} 8^{+}$ cells per unit of tumor area.

To trigger CAC formation, we treated 8- to 14-week-old female mice with $12.5 \mathrm{mg} / \mathrm{kg}$ of the procarcinogen AOM via i.p. injection, followed by 3 cycles of alternating administration of DSS in drinking water (cycle 1: $2.0 \%, 5$ days; cycle 2: $2.0 \%, 4$ days; cycle 3: $2 \%, 4$ days) and regular water (16 days). The end point was set to 14 weeks, when mice were sacrificed. Colons were flushed with PBS and cut longitudinally to expose tumors. At this stage, colon lesions appeared to be either hyperplasia or adenoma and mostly developed in the distal colon and rectum. Macroscopic tumors were counted across the whole colon and rectum. The diameter of each tumor was measured using a digital caliper (Fisher Scientific). The murine CAC grading system was established based on ref. 113. Briefly, hyperplasia was defined as lesions showing increased cytoplasmic basophilia and elongated glandular architecture with no compression to neighboring glands; atypical hyperplasia was defined as hyperplastic lesions showing features of cellular atypia such as loss of polarity of epithelial cells and/or crypt atypia such as dilated or shrunk lumen, lumen with multiple surrounding epithelial layers, or reduced goblet cells within lumens; adenoma was defined as lesions that are compressive to neighboring glands and display features of disorga- nized glandular architecture and increased mitotic figures, and may be polypoid and contain crypt abscesses; atypical adenoma was defined as adenomas showing increased mitotic figures or signs of muscularis mucosae penetration; adenocarcinoma was definite when invasion of basement membrane or submucosa was present. Tumor cell mitosis was determined by counting mitotic figures per high-power $(\times 40)$ fields in the lesion that contained the highest number of mitotic figures. TAM density was determined by counting $\mathrm{CD}^{+} 8^{+}$cells on a $\times 20$ field for 3 fields using MetaMorph software.

Immunohistochemistry. Immunohistochemistry was performed on sections from paraffin-embedded samples according to the manufacturer's guidelines (Vector Laboratories). Primary antibodies used included rat antimouse Ly-6G/Gr-1 (eBioscience) at 1:100 dilution, mouse anti- $\alpha$-SMA monoclonal antibody (Sigma-Aldrich) at 1:400 dilution, and mouse antiCD68 monoclonal antibody (Abcam) at 1:100 dilution. Vector Laboratories biotinylated anti-rat IgG was used as the secondary antibody at a 1:200 dilution with the rat primary antibodies. A Vector Laboratories M.O.M. Kit was used to aid in the detection of mouse antigen using mouse primary antibodies. Sections were incubated with DAB substrate (Vector Laboratories) and counterstained with hematoxylin.

Statistics. Data are represented as mean \pm SEM, except those of Taqman gene expression assays, which are represented as mean \pm SD. Unpaired 2-tailed Student's $t$ test was preformed for most of the studies to evaluate the differences between the control and HIF- $2 \alpha$-deficient groups. For CAC tumor number and tumor size studies, the 2 -sample $t$ test for independent samples with equal variances was used. For CAC tumor stage and mitosis evaluation, Wilcoxon rank-sum test was performed due to non-normal data distribution. The Kolmogorov-Smirnov test was used for all normality tests. $P \leq 0.05$ was considered statistically significant.

\section{Acknowledgments}

The authors are thankful to Steve Reiner, Kim Nichols, and Hao Shen for thoughtful suggestions; Theresa Richardson and Carmella Romeo for technical assistance; and Hongwei Yu for histological sample preparation. This work was supported by NIH grant 66310 (to M.C. Simon), the Howard Hughes Medical Institute (HHMI), and the Abramson Family Cancer Research Institute. E.P. Williams was supported by the HHMI Medical Fellows Program. M.M. Hickey was supported by an HHMI Predoctoral Fellowship in Biological Sciences. M.C. Simon is an investigator of the Howard Hughes Medical Institute.

Received for publication January 14, 2010, and accepted in revised form June 1, 2010.

Address correspondence to: M. Celeste Simon, Howard Hughes Medical Institute, Abramson Family Cancer Research Institute, University of Pennsylvania School of Medicine, 456 BRB II/III, 421 Curie Boulevard, Philadelphia, Pennsylvania 19104-6160, USA. Phone: 215.746.5532; Fax: 215.746.5511; E-mail: celeste2@ mail.med.upenn.edu.
1. Mosser DM, Edwards JP. Exploring the full spectrum of macrophage activation. Nat Rev Immunol. 2008;8(12):958-969.

2. Rutherford MS, Witsell A, Schook LB. Mechanisms generating functionally heterogeneous macrophages: chaos revisited. J Lenkoc Biol. 1993;53(5):602-618.

3. Stout RD, Suttles J. Functional plasticity of macrophages: reversible adaptation to changing microenvironments. J Leukoc Biol. 2004;76(3):509-513.
4. Gordon S. Alternative activation of macrophages. Nat Rev Immunol. 2003;3(1):23-35.

5. Benoit M, Desnues B, Mege JL. Macrophage polarization in bacterial infections. J Immunol. 2008;181(6):3733-3739.

6. Szlosarek P, Charles KA, Balkwill FR. Tumour necrosis factor-alpha as a tumour promoter. Eur J Cancer. 2006;42(6):745-750.

7. Van Ginderachter JA, et al. Classical and alternative activation of mononuclear phagocytes: picking the best of both worlds for tumor promotion. Immunobiology. 2006;211(6-8):487-501.

8. Crowther M, Brown NJ, Bishop ET, Lewis CE. Microenvironmental influence on macrophage regulation of angiogenesis in wounds and malignant tumors. J Leukoc Biol. 2001;70(4):478-490.

9. Pollard JW. Tumour-educated macrophages promote tumour progression and metastasis. Nat Rev Cancer. 2004;4(1):71-78

10. Sica A, Schioppa T, Mantovani A, Allavena P. 
Tumour-associated macrophages are a distinct M2 polarised population promoting tumour progression: potential targets of anti-cancer therapy. Eur J Cancer. 2006;42(6):717-727.

11. Klimp AH, de Vries EG, Scherphof GL, Daemen $\mathrm{T}$. A potential role of macrophage activation in the treatment of cancer. Crit Rev Oncol Hematol. 2002;44(2):143-161.

12. Romieu-Mourez R, et al. Distinct roles for IFN regulatory factor (IRF)-3 and IRF-7 in the activation of antitumor properties of human macrophages. Cancer Res. 2006;66(21):10576-10585.

13. Murdoch C, Giannoudis A, Lewis CE. Mechanisms regulating the recruitment of macrophages into hypoxic areas of tumors and other ischemic tissues. Blood. 2004;104(8):2224-2234.

14. Murdoch C, Lewis CE. Macrophage migration and gene expression in response to tumor hypoxia. Int $J$ Cancer. 2005;117(5):701-708.

15. Lewis CE, Pollard JW. Distinct role of macrophages in different tumor microenvironments. Cancer Res. 2006;66(2):605-612.

16. Murdoch C, Muthana M, Lewis CE. Hypoxia regulates macrophage functions in inflammation. J Immunol. 2005;175(10):6257-6263.

17. Bjornheden T, Levin M, Evaldsson M, Wiklund $\mathrm{O}$. Evidence of hypoxic areas within the arterial wall in vivo. Arterioscler Thromb Vasc Biol. 1999; 19(4):870-876

18. Lund-Olesen K. Oxygen tension in synovial fluids. Arthritis Rheum. 1970;13(6):769-776.

19. Peters CL, Morris CJ, Mapp PI, Blake DR, Lewis CE, Winrow VR. The transcription factors hypoxia-inducible factor 1alpha and Ets-1 colocalize in the hypoxic synovium of inflamed joints in adjuvant-induced arthritis. Arthritis Rheum. 2004;50(1):291-296.

20. Vaupel P, Kelleher DK, Hockel M. Oxygen status of malignant tumors: pathogenesis of hypoxia and significance for tumor therapy. Semin Oncol. 2001;28(2 suppl 8):29-35

21. Simon MC, Keith B. The role of oxygen availability in embryonic development and stem cell function. Nat Rev Mol Cell Biol. 2008;9(4):285-296.

22. Covello KL, Simon MC. HIFs, hypoxia, and vascular development. Curr Top Dev Biol. 2004;62:37-54.

23. Kaelin WGJr, Ratcliffe PJ. Oxygen sensing by metazoans: the central role of the HIF hydroxylase pathway. Mol Cell. 2008;30(4):393-402.

24. Tian H, McKnight SL, Russell DW. Endothelial PAS domain protein 1 (EPAS1), a transcription factor selectively expressed in endothelial cells. Genes Dev. 1997;11(1):72-82.

25. Wiesener MS, et al. Widespread hypoxia-inducible expression of HIF-2alpha in distinct cell populations of different organs. FASEB J. 2003;17(2):271-273.

26. Ema M, Taya S, Yokotani N, Sogawa K, Matsuda Y, Fujii-Kuriyama Y. A novel bHLH-PAS factor with close sequence similarity to hypoxia-inducible factor 1alpha regulates the VEGF expression and is potentially involved in lung and vascular development. Proc Natl Acad Sci US A. 1997;94(9):4273-4278.

27. Hu CJ, Wang LY, Chodosh LA, Keith B, Simon MC. Differential roles of hypoxia-inducible factor 1alpha (HIF-1alpha) and HIF-2alpha in hypoxic gene regulation. Mol Cell Biol. 2003;23(24):9361-9374.

28. Covello KL, et al. HIF-2alpha regulates Oct-4: effects of hypoxia on stem cell function, embryonic development, and tumor growth. Genes Dev. 2006;20(5):557-570.

29. Gruber M, Hu CJ, Johnson RS, Brown EJ, Keith B, Simon MC. Acute postnatal ablation of Hif2alpha results in anemia. Proc Natl Acad Sci U S A. 2007;104(7):2301-2306.

30. Koshiji M, Kageyama Y, Pete EA, Horikawa I, Barrett JC, Huang LE. HIF-1alpha induces cell cycle arrest by functionally counteracting Myc. EMBOJ. 2004;23(9):1949-1956.

31. Koshiji M, et al. HIF-1alpha induces genetic insta- bility by transcriptionally downregulating MutSalpha expression. Mol Cell. 2005;17(6):793-803.

32. Gordan JD, Bertout JA, Hu CJ, Diehl JA, Simon MC. HIF-2alpha promotes hypoxic cell proliferation by enhancing c-myc transcriptional activity. Cancer Cell. 2007;11(4):335-347.

33. Gordan JD, et al. HIF-alpha effects on c-Myc distinguish two subtypes of sporadic VHLdeficient clear cell renal carcinoma. Cancer Cell. 2008;14(6):435-446.

34. Bertout JA, et al. HIF2alpha inhibition promotes p53 pathway activity, tumor cell death, and radiation responses. Proc Natl Acad Sci U S A. 2009;106(34):14391-14396.

35. Moeller BJ, et al. Pleiotropic effects of HIF-1 blockade on tumor radiosensitivity. Cancer Cell. 2005;8(2):99-110.

36. Griffiths L, et al. The macrophage - a novel system to deliver gene therapy to pathological hypoxia. Gene Ther. 2000;7(3):255-262.

37. Burke B, et al. Expression of HIF-1alpha by human macrophages: implications for the use of macrophages in hypoxia-regulated cancer gene therapy. J Pathol. 2002;196(2):204-212.

38. Talks KL, et al. The expression and distribution of the hypoxia-inducible factors HIF-1alpha and HIF-2alpha in normal human tissues, cancers, and tumor-associated macrophages. Am J Pathol. 2000;157(2):411-421.

39. Cramer $T$, et al. HIF-1alpha is essential for myeloid cell-mediated inflammation. Cell. 2003;112(5):645-657

40. Peyssonnaux C, et al. HIF-1alpha expression regulates the bactericidal capacity of phagocytes. J Clin Invest. 2005;115(7):1806-1815.

41. Peyssonnaux C, Cejudo-Martin P, Doedens A, Zinkernagel AS, Johnson RS, Nizet V. Cutting edge: Essential role of hypoxia inducible factor-1alpha in development of lipopolysaccharide-induced sepsis. J Immunol. 2007;178(12):7516-7519.

42. Clausen BE, Burkhardt C, Reith W, Renkawitz $\mathrm{R}$, Forster I. Conditional gene targeting in macrophages and granulocytes using LysMcre mice. Transgenic Res. 1999;8(4):265-277.

43. Wiesener MS, et al. Induction of endothelial PAS domain protein-1 by hypoxia: characterization and comparison with hypoxia-inducible factor-1alpha. Blood. 1998;92(7):2260-2268.

44. Wang V, Davis DA, Haque M, Huang LE, Yarchoan R. Differential gene up-regulation by hypoxiainducible factor-1alpha and hypoxia-inducible factor-2alpha in HEK293T cells. Cancer Res. 2005;65(8):3299-3306.

45. Baugh JA, Gantier M, Li L, Byrne A, Buckley A, Donnelly SC. Dual regulation of macrophage migration inhibitory factor (MIF) expression in hypoxia by CREB and HIF-1. Biochem Biophys Res Commun. 2006;347(4):895-903.

46. Zampetaki A, Mitsialis SA, Pfeilschifter J, Kourembanas S. Hypoxia induces macrophage inflammatory protein-2 (MIP-2) gene expression in murine macrophages via NF-kappaB: the prominent role of p42/ p44 and PI3 kinase pathways. FASEB J. 2004;18(10):1090-1092.

47. Ohnishi S, Yasuda T, Kitamura S, Nagaya N. Effect of hypoxia on gene expression of bone marrowderived mesenchymal stem cells and mononuclear cells. Stem Cells. 2007;25(5):1166-1177.

48. Akashi K, Traver D, Miyamoto T, Weissman IL. A clonogenic common myeloid progenitor that gives rise to all myeloid lineages. Nature. 2000;404(6774):193-197.

49. Mecklenburgh KI, et al. Involvement of a ferroprotein sensor in hypoxia-mediated inhibition of neutrophil apoptosis. Blood. 2002;100(8):3008-3016.

50. Walmsley SR, et al. Hypoxia-induced neutrophil survival is mediated by HIF-1alpha-dependent NFkappaB activity. J Exp Med. 2005;201(1):105-115.
51. Kumar A, Thota V, Dee L, Olson J, Uretz E, Parrillo JE. Tumor necrosis factor alpha and interleukin 1 beta are responsible for in vitro myocardial cell depression induced by human septic shock serum. J Exp Med. 1996;183(3):949-958.

52. Tracey KJ, et al. Anti-cachectin/TNF monoclonal antibodies prevent septic shock during lethal bacteraemia. Nature. 1987;330(6149):662-664.

53. Dinarello CA. The proinflammatory cytokines interleukin-1 and tumor necrosis factor and treatment of the septic shock syndrome. J Infect Dis. 1991;163(6):1177-1184.

54. Zisman DA, et al. Anti-interleukin-12 therapy protects mice in lethal endotoxemia but impairs bacterial clearance in murine Escherichia coli peritoneal sepsis. Shock. 1997;8(5):349-356.

55. Doherty GM, Lange JR, Langstein HN, Alexander HR, Buresh CM, Norton JA. Evidence for IFNgamma as a mediator of the lethality of endotoxin and tumor necrosis factor-alpha. J Immunol. 1992;149(5):1666-1670.

56 . Heinzel FP. The role of IFN-gamma in the pathology of experimental endotoxemia. J Immunol. 1990;145(9):2920-2924

57. Jean-Baptiste E. Cellular mechanisms in sepsis. Intensive Care Med. 2007;22(2):63-72.

58. Ulloa L, Tracey KJ. The "cytokine profile": a code for sepsis. Trends Mol Med. 2005;11(2):56-63.

59. Kozak W, Zheng H, Conn CA, Soszynski D, van der Ploeg LH, Kluger MJ. Thermal and behavioral effects of lipopolysaccharide and influenza in interleukin-1 beta-deficient mice. Am J Physiol. 1995;269(5 pt 2):R969-977.

60. Parrillo JE. Pathogenetic mechanisms of septic shock. NEngl J Med. 1993;328(20):1471-1477.

61. Levy RJ, Deutschman CS. Evaluating myocardial depression in sepsis. Shock. 2004;22(1):1-10.

62. Tavener SA, Kubes P. Cellular and molecular mechanisms underlying LPS-associated myocyte impairment. Am J Physiol Heart Circ Physiol. 2006;290(2):H800-806.

63. Nemoto S, et al. Escherichia coli LPS-induced LV dysfunction: role of toll-like receptor- 4 in the adult heart. Am J Physiol Heart Circ Physiol. 2002;282(6):H2316-2323.

64. Knuefermann P, et al. CD14-deficient mice are protected against lipopolysaccharide-induced cardiac inflammation and left ventricular dysfunction. Circulation. 2002;106(20):2608-2615.

65. Howard M, Muchamuel T, Andrade S, Menon S. Interleukin 10 protects mice from lethal endotoxemia. J Exp Med. 1993;177(4):1205-1208.

66. Standiford TJ, Strieter RM, Lukacs NW, Kunkel SL. Neutralization of IL-10 increases lethality in endotoxemia. Cooperative effects of macrophage inflammatory protein- 2 and tumor necrosis factor. J Immunol. 1995;155(4):2222-2229.

67. Nicoletti F, et al. Endotoxin-induced lethality in neonatal mice is counteracted by interleukin-10 (IL-10) and exacerbated by anti-IL-10. Clin Diagn Lab Immunol. 1997;4(5):607-610.

68. Marchant A, et al. Interleukin-10 controls interferon-gamma and tumor necrosis factor production during experimental endotoxemia. Eur J Immunol. 1994;24(5):1167-1171.

69. Hack CE, Zeerleder S. The endothelium in sepsis: source of and a target for inflammation. Crit Care Med. 2001;29(7 suppl):S21-27.

70. Kawai T, Akira S. TLR signaling. Cell Death Differ. 2006;13(5):816-825.

71. Pahl HL. Activators and target genes of Rel/NFkappaB transcription factors. Oncogene. 1999; 18(49):6853-6866.

72. Wenger RH, Stiehl DP, Camenisch G. Integration of oxygen signaling at the consensus HRE. Sci STKE. 2005;2005(306):re12.

73. Nakadate T, Yamamoto S, Aizu E, Kato R. Inhibition of 12-O-tetradecanoylphorbol-13-acetate- 
induced increase in vascular permeability in mouse skin by lipoxygenase inhibitors. Jpn J Pharmacol. 1985;38(2):161-168.

74. Raick AN. Ultrastructural, histological, and biochemical alterations produced by 12 -O-tetradecanoyl-phorbol-13-acetate on mouse epidermis and their relevance to skin tumor promotion. Cancer Res. 1973;33(2):269-286.

75. Fortier AH, Hoover DL, Nacy CA. Intracellular replication of Leishmania tropica in mouse peritoneal macrophages: amastigote infection of resident cells and inflammatory exudate macrophages. Infect Immun. 1982;38(3):1304-1308.

76. Hoover DL, Nacy CA. Macrophage activation to kill Leishmania tropica: defective intracellular killing of amastigotes by macrophages elicited with sterile inflammatory agents. J Immunol. 1984;132(3):1487-1493.

77. Leek RD, et al. Relation of hypoxia-inducible factor-2 alpha (HIF-2 alpha) expression in tumor-infiltrative macrophages to tumor angiogenesis and the oxidative thymidine phosphorylase pathway in Human breast cancer. Cancer Res. 2002;62(5):1326-1329.

78. Kawanaka T, Kubo A, Ikushima H, Sano T, Takegawa Y, Nishitani H. Prognostic significance of HIF-2alpha expression on tumor infiltrating macrophages in patients with uterine cervical cancer undergoing radiotherapy. J Med Invest. 2008;55(1-2):78-86.

79. Maeda S, Kamata H, Luo JL, Leffert H, Karin M. IKKbeta couples hepatocyte death to cytokinedriven compensatory proliferation that promotes chemical hepatocarcinogenesis. Cell. 2005; 121(7):977-990.

80. Naugler WE, et al. Gender disparity in liver cancer due to sex differences in MyD88-dependent IL-6 production. Science. 2007;317(5834):121-124.

81. Sakurai T, Maeda S, Chang L, Karin M. Loss of hepatic NF-kappa B activity enhances chemical hepatocarcinogenesis through sustained c-Jun Nterminal kinase 1 activation. Proc Natl Acad Sci US A. 2006;103(28):10544-10551.

82. Gillen CD, Walmsley RS, Prior P, Andrews HA, Allan RN. Ulcerative colitis and Crohn's disease: a comparison of the colorectal cancer risk in extensive colitis. Gut. 1994;35(11):1590-1592.

83. Itzkowitz SH, Yio X. Inflammation and cancer IV. Colorectal cancer in inflammatory bowel disease: the role of inflammation. Am J Physiol Gastrointest Liver Physiol. 2004;287(1):G7-17.

84. Janne PA, Mayer RJ. Chemoprevention of colorectal cancer. N Engl J Med. 2000;342(26):1960-1968.

85. Greten FR, et al. IKKbeta links inflammation and tumorigenesis in a mouse model of colitis-associated cancer. Cell. 2004;118(3):285-296.
86. Karin M, Lawrence T, Nizet V. Innate immunity gone awry: linking microbial infections to chronic inflammation and cancer. Cell. 2006;124(4):823-835.

87. Okayasu I, Ohkusa T, Kajiura K, Kanno J, Sakamoto $\mathrm{S}$. Promotion of colorectal neoplasia in experimental murine ulcerative colitis. Gut. 1996;39(1):87-92.

88. Hayakawa Y, et al. Apoptosis Signal-Regulating Kinase 1 regulates colitis and colitis-associated tumorigenesis via the innate immune responses. Gastroenterology. 2009;138(3):1055-1067.

89. Fukata $M$, et al. Innate immune signaling by Tolllike receptor-4 (TLR4) shapes the inflammatory microenvironment in colitis-associated tumors. Inflamm Bowel Dis. 2009;15(7):997-1006.

90. Hoffmann A, Xia Y, Verma IM. Inflammatory tales of liver cancer. Cancer Cell. 2007;11(2):99-101.

91. Luedde T, et al. Deletion of NEMO/IKKgamma in liver parenchymal cells causes steatohepatitis and hepatocellular carcinoma. Cancer Cell. 2007;11(2):119-132.

92. Owen KA, et al. Regulation of lamellipodial persistence, adhesion turnover, and motility in macrophages by focal adhesion kinase. J Cell Biol. 2007;179(6):1275-1287

93. Gong Y, Hart E, Shchurin A, Hoover-Plow J. Inflammatory macrophage migration requires MMP-9 activation by plasminogen in mice. J Clin Invest. 2008;118(9):3012-3024.

94. Blades MC, et al. Stromal cell-derived factor 1 (CXCL12) induces monocyte migration into human synovium transplanted onto SCID mice. Arthritis Rheum. 2002;46(3):824-836.

95. Schioppa T, et al. Regulation of the chemokine receptor CXCR4 by hypoxia. J Exp Med. 2003;198(9):1391-1402.

96. Pankov R, Yamada KM. Fibronectin at a glance. J Cell Sci. 2002;115(pt 20):3861-3863.

97. Kung AL, Wang S, Klco JM, Kaelin WG, Livingston DM. Suppression of tumor growth through disruption of hypoxia-inducible transcription. Nat Med. 2000;6(12):1335-1340.

98. Liao D, Corle C, Seagroves TN, Johnson RS. Hypoxia-inducible factor-1alpha is a key regulator of metastasis in a transgenic model of cancer initiation and progression. Cancer Res. 2007;67(2):563-572.

99. Kondo K, Klco J, Nakamura E, Lechpammer M, Kaelin WG Jr. Inhibition of HIF is necessary for tumor suppression by the von Hippel-Lindau protein. Cancer Cell. 2002;1(3):237-246.

100.Maranchie JK, Vasselli JR, Riss J, Bonifacino JS, Linehan WM, Klausner RD. The contribution of VHL substrate binding and HIF1-alpha to the phenotype of VHL loss in renal cell carcinoma. Cancer Cell. 2002;1(3):247-255.
101.Giatromanolaki A, et al. Relation of hypoxia inducible factor 1 alpha and 2 alpha in operable non-small cell lung cancer to angiogenic/molecular profile of tumours and survival. Br J Cancer. 2001;85(6):881-890.

102. Holmquist-Mengelbier L, et al. Recruitment of HIF-1alpha and HIF-2alpha to common target genes is differentially regulated in neuroblastoma: HIF-2alpha promotes an aggressive phenotype. Cancer Cell. 2006;10(5):413-423.

103. White JR, et al. Genetic amplification of the transcriptional response to hypoxia as a novel means of identifying regulators of angiogenesis. Genomics. 2004;83(1):1-8.

104. Takeda N, et al. Differential activation and antagonistic function of HIF-\{alpha\} isoforms in macrophages are essential for $\mathrm{NO}$ homeostasis. Genes Dev. 2010;24(5):491-501.

105.Tian H, Hammer RE, Matsumoto AM, Russell DW, McKnight SL. The hypoxia-responsive transcription factor EPAS1 is essential for catecholamine homeostasis and protection against heart failure during embryonic development. Genes Dev. 1998;12(21):3320-3324

106.Compernolle V, et al. Loss of HIF-2alpha and inhibition of VEGF impair fetal lung maturation, whereas treatment with VEGF prevents fatal respiratory distress in premature mice. Nat Med. 2002;8(7):702-710.

107. Peng J, Zhang L, Drysdale L, Fong GH. The transcription factor EPAS-1/hypoxia-inducible factor 2alpha plays an important role in vascular remodeling. Proc Natl Acad Sci U S A. 2000;97(15):8386-8391.

108. Hannah S, et al. Hypoxia prolongs neutrophil survival in vitro. FEBS Lett. 1995;372(2-3):233-237.

109.Jantsch J, et al. Hypoxia and hypoxia-inducible factor- 1 alpha modulate lipopolysaccharide-induced dendritic cell activation and function. J Immunol. 2008;180(7):4697-4705.

110.Corraliza IM, Campo ML, Soler G, Modolell M. Determination of arginase activity in macrophages: a micromethod. J Immunol Methods. 1994; 174(1-2):231-235.

111.Lenox LE, et al. Mutation of tyrosine 145 of lymphocyte cytosolic protein 2 protects mice from anaphylaxis and arthritis. J Allergy Clin Immunol. 2009;124(5):1088-1098.

112.Lutz MB, et al. An advanced culture method for generating large quantities of highly pure dendritic cells from mouse bone marrow. J Immunol Methods. 1999;223(1):77-92

113. Mohr U, ed. International Classification Of Rodent Tumors. Part II: The Mouse. New York, New York, USA: Springer-Verlag Berlin Heidelberg; 2001. 